\title{
Differentially imprinted innate immunity by mucosal boost vaccination determines antituberculosis immune protective outcomes, independent of T-cell immunity
}

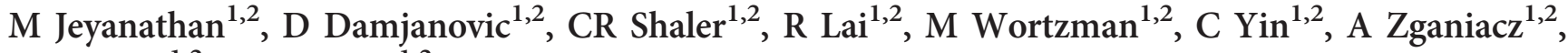 \\ BD Lichty ${ }^{1,2}$ and Z Xing ${ }^{1,2}$
}

Homologous and heterologous parenteral prime-mucosal boost immunizations have shown great promise in combating mucosal infections such as tuberculosis and AIDS. However, their immune mechanisms remain poorly defined. In particular, it is still unclear whether T-cell and innate immunity may be independently affected by these immunization modalities and how it impacts immune protective outcome. Using two virus-based tuberculosis vaccines (adenovirus (Ad) and vesicular stomatitis virus (VSV) vectors), we found that while both homologous (Ad/Ad) and heterologous (Ad/VSV) respiratory mucosal boost immunizations elicited similar T-cell responses in the lung, they led to drastically different immune protective outcomes. Compared with Ad-based boosting, VSV-based boosting resulted in poorly enhanced protection against tuberculosis. Such inferior protection was associated with differentially imprinted innate phagocytes, particularly the $\mathrm{CD} 11 \mathrm{c}^{+} \mathrm{CD}_{11} \mathrm{~b}^{+/-}$cells, in the lung. We identified heightened type 1 interferon (IFN) responses to be the triggering mechanism. Thus, increased IFN- $\beta$ severely blunted interleukin-12 responses in infected phagocytes, which in turn impaired their nitric oxide production and antimycobacterial activities. Our study reveals that vaccine vectors may differentially imprint innate cells at the mucosal site of immunization, which can impact immuneprotective outcome, independent of T-cell immunity, and it is of importance to determine both T-cell and innate cell immunity in vaccine studies.

\section{INTRODUCTION}

Prime-boost immunization modalities have proven a powerful way of vaccination. ${ }^{1-3}$ In this regard, live attenuated viralvectored vaccines have been frequently used for developing either homologous or heterologous prime-boost immunization strategies against infections by a number of intracellular pathogens, including Mycobacterium tuberculosis (M.tb), HIV, and malaria for which effective vaccines are lacking. ${ }^{4-8}$ As many intracellular pathogens such as M.tb and HIV gain their entry via a mucosal route, the capability of a given immunization strategy to induce effective mucosal immunity is the key to immune protection. ${ }^{9}$ Mounting evidence suggests that administering a vaccine at a peripheral site followed by giving the same (homologous) or a different (heterologous) vaccine via the mucosal site of pathogen entry (parenteral prime-mucosal boost immunization) is the most promising as this immunization modality installs robust mucosal immunity while providing strong systemic immunity to protect from systemic dissemination of mucosal infection. ${ }^{6,10-13}$ However, the relative potency and immune mechanisms of such homologous and heterologous mucosal boost immunizations still remain poorly defined.

It is well accepted that T-cell immunity is most critically required for host defense against mucosal intracellular pathogens such as $M . t b .^{2,14-16}$ The $\mathrm{T}$ cell has its role primarily by activating infected innate phagocytic cells (macrophages/

${ }^{1}$ Department of Pathology and Molecular Medicine, McMaster Immunology Research Centre, McMaster University, Hamilton, Ontario, Canada and ${ }^{2}$ MG DeGroote Institute for Infectious Disease Research, McMaster University, Hamilton, Ontario, Canada. Correspondence: Z Xing (xingz@mcmaster.ca) 
dendritic cells). ${ }^{14,15,17}$ Thus, the level and quality of T-cell immunity has been traditionally used to predict the potency and immune-protective potential of tuberculosis (TB) immunization strategies. ${ }^{18-20}$ However, recent emerging evidence suggests that protective immunity against primary pulmonary tuberculous infection requires not only T-cell immunity but also the responsive or functioning innate phagocytic cells and that host defense may still fail because of defective innate immunity even when T-cell immunity remains intact. ${ }^{14,21-24}$ Whether both T-cell and innate immunity may be independently affected by $\mathrm{TB}$ vaccination and how this impacts immune protective outcomes are largely unclear. This represents an important issue, particularly relevant to mucosal boost immunization strategies as the mucosally delivered vaccine can act directly on innate effector cells right at the site of pathogen entry, the immunological battleground. ${ }^{9,25}$ Enhanced knowledge in this regard thus holds important implications in developing novel effective mucosal immunization strategies to combat not only pulmonary TB but also other mucosal infectious diseases, such as influenza, AIDS, and Chlamydia.

In this study, we have investigated this issue in murine models with the two model viral-vectored vaccines: recombinant adenovirus-vectored (AdAg85A) and vesicular stomatitis virus-vectored vaccines (VSVAg85A), both of which were engineered to express an immunodominant $M$.tb antigen ( $\mathrm{Ag})$, Ag85A. Thus, following parenteral intramuscular prime immunization with AdAg85A, the animals were subject to respiratory mucosal boost immunization either with AdAg85A (homologous) or VSVAg85A (heterologous) vaccine. We have found that while both Ad and VSV mucosal boost immunizations elicit comparable Ag-specific T-cell responses, they lead to a markedly different immuneprotective outcome upon mucosal M.tb challenge. We further identify that the inferior protection by VSV boost immunization is associated with differentially imprinted innate immunity via a type 1 interferon (IFN)-mediated mechanism. Our findings together suggest that vaccine vectors may differentially imprint the innate effector cells at the mucosal site of immunization, which can determine the immune-protective outcome, independent of T-cell immunity, and highlight the importance of examining both $\mathrm{T}$-cell and innate immune cell responses for vaccine evaluation.

\section{RESULTS}

Homologous Ad/Ad respiratory mucosal boost immunization enhances $M$.tb Ag-specific T-cell responses in the lung following parenteral prime immunization

Studies have shown that the pre-existing antiviral antibody $\mathrm{Ab})$ responses by parenteral prime immunization can blunt the immunogenicity of subsequent parenteral boost immunization with the same vaccine. ${ }^{26-28}$ However, recent studies suggest that such limitations can be overcome by administering the same viral boost vector via a mucosal route in a homologous parenteral prime-mucosal boost immunization modality. ${ }^{12,13}$ To verify whether this would hold true specifically for homologous intramuscular prime-respiratory mucosal boost immunization, mice were prime-immunized intramuscularly with a recombinant adenovirus expressing an immunodominant M.tb Ag Ag85A (AdAg85A) and subsequently boostimmunized intranasally with AdAg85A (Ad/Ad). The control group received only intranasal phosphate-buffered saline (PBS) delivery (Ad/PBS). At 2 weeks after boost, Ag-specific T-cell responses were examined in the bronchoalveolar lavage (BAL), lung interstitium, and spleen by Ag85A tetramer immunostaining and intracellular cytokine immunostaining. Consistent with our previous reports, ${ }^{29}$ parenteral intramuscular AdAg85A prime immunization (Ad/PBS) alone induced tetramer (tet) ${ }^{+}$and IFN- $\gamma^{+} \mathrm{CD} 8 \mathrm{~T}$-cell responses in the lung and spleen, but not in the airway lumen (BAL) (Table 1). In comparison, homologous intranasal mucosal boost immunization with the same AdAg85A vaccine markedly increased the number of Ag-specific CD8 T-cell responses both in the BAL and lung interstitium, but not in the spleen (Table 1). These data indicate that indeed homologous Advectored respiratory mucosal boost immunization is able to enhance potently Ag-specific T-cell responses within the lung following parenteral intramuscular prime immunization.

\section{Homologous Ad/Ad and heterologous Ad/VSV respiratory mucosal boost immunizations elicit similar M.tb Ag- specific T-cell responses in the lung and peripheral sites} Having established that homologous Ad viral-vectored respiratory mucosal boost immunization could enhance Ag-specific T-cell responses in the lung following parenteral prime immunization, we set out to compare the immunogenicity (T-cell activation) by homologous and heterologous respiratory

Table 1 Homologous viral-vectored respiratory mucosal boost immunization enhances M.tb Ag-specific T-cell responses in the lung following parenteral prime immunization

\begin{tabular}{|c|c|c|c|c|c|c|}
\hline & \multicolumn{2}{|c|}{$\mathrm{BAL}$} & \multicolumn{2}{|c|}{ Lung } & \multicolumn{2}{|c|}{ Spleen } \\
\hline & Ad/PBS & $\mathrm{Ad} / \mathrm{Ad}$ & Ad/PBS & $\mathrm{Ad} / \mathrm{Ad}$ & Ad/PBS & $\mathrm{Ad} / \mathrm{Ad}$ \\
\hline $\mathrm{CD}^{+}$tet $^{+}\left(10^{3}\right)$ & $0.1 \pm 0.02$ & $2.6 \pm 0.9$ & $6.9 \pm 1.7$ & $46.0 \pm 15.7$ & $73.6 \pm 7.6$ & $28.5 \pm 5.8$ \\
\hline $\mathrm{CD}^{+} \mathrm{IFN}^{-} \gamma^{+}\left(10^{3}\right)$ & $0.09 \pm 0.007$ & $4.0 \pm 1.7$ & $7.75 \pm 1.2$ & $51.3 \pm 20.2$ & $112.7 \pm 13.3$ & $36.4 \pm 10.4$ \\
\hline
\end{tabular}

Abbreviations: Ad, adenovirus; AdAg85A, recombinant adenovirus expressing an immunodominant M.tb Ag Ag85A Ag, antigen; BAL, bronchoalveolar lavage; ICCS, intracellular cytokine immunostaining; IFN, interferon; i.m., intramuscularly; i.n., intranasal; M.tb, Mycobacterium tuberculosis; PBS, phosphate-buffered saline. Mice were prime-immunized i.m. with a recombinant adenovirus expressing an immunodominant M.tb antigen Ag85A (AdAg85A) and subsequently boost-immunized i.n. with AdAg85A (Ad/Ad). The control group received only i.n. PBS delivery (Ad/PBS). At 2 weeks after boost, Ag-specific T-cell responses were examined in the BAL, lung interstitium,

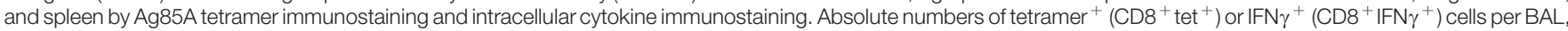
lung, and spleen are tabulated. The data are expressed as mean \pm s.e.m. of cell numbers from three animals per group, representative of two independent experiments. 
mucosal boost immunizations. T-cell immunity has long been considered to be the key to anti-TB protection. ${ }^{2,14-16}$ To this end, all groups of mice were prime-immunized intramuscularly with AdAg85A, and 3 weeks after priming, they were boost-immunized intranasally either with AdAg85A (homologous boost; Ad/Ad group) or with a heterologous recombinant vesicular stomatitis virus-vectored vaccine expressing Ag85A (VSVAg85A (heterologous boost; Ad/VSV group). Ag-specific T-cell responses in the BAL, lung, and spleen were compared 2 weeks after boosting (Figure 1a). Although compared with homologous Ad mucosal boost immunization, heterologous VSV mucosal boost led to greater frequencies of tet ${ }^{+}$and IFN $-\gamma^{+}$CD8 T cells, particularly in the airway lumen (BAL) (Figure 1b), the absolute numbers of Ag-specific CD8 T-cell responses were comparable in the BAL, lung, and spleen between homologous and heterologous mucosal boost immunizations (Figure 1c; the appearing differences between $\mathrm{Ad} / \mathrm{Ad}$ and Ad/VSV in the middle panel were not statistically different: $P=0.33$ for tet ${ }^{+} ; \quad P=0.5$ for IFN $-\gamma^{+}$groups). These results indicate that both Ad and VSV mucosal boost immunizations induce similarly activated CD8 $\mathrm{T}$-cell responses in the lung and peripheral lymphoid tissues.

\section{Homologous Ad respiratory mucosal boost immunization provides much better anti-TB immune protection than heterologous VSV boost immunization}

To investigate whether similarly increased $\mathrm{T}$ cells in the BAL and lung interstitium by Ad and VSV mucosal boost immunizations could translate into similarly improved immune protection from pulmonary M.tb challenge, mice were prime- and boost-immunized as described in Figure 1a, and subsequently challenged via the airway with virulent M.tb at 2 weeks postboosting and killed for assessment of levels of M.tb infection in the lung and spleen at 4 weeks postchallenge (Figure 2a). A group of completely unimmunized mice were also M.tb-challenged as a naive control. As expected, unimmunized mice (naive) had high levels of infection both in the lung and spleen (Figure 2b, c). When the mice were challenged at 2 weeks postboosting, homologous boost immunization with AdAg85A (Ad/Ad) remarkably reduced infection in the lung by about $2 \log$ (Figure 2b). In contrast, surprisingly heterologous boost immunization with VSVAg85A (Ad/VSV) only modestly reduced the level of infection in the lung $(0.4 \mathrm{log})$ compared with naive animals (Figure 2b). Highly reduced levels of infection were also seen in the spleen of Ad/Ad animals, whereas only moderately reduced

a

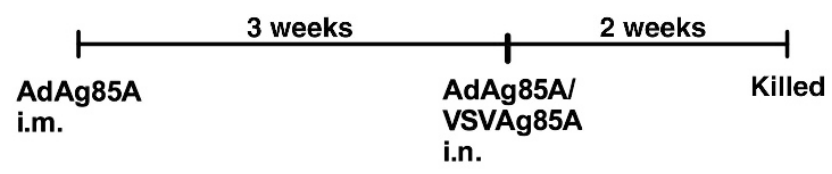

b

BAL

Lung $\mathrm{CD}^{+}$tet $^{+} \mathrm{CD}^{+}{ }^{+} \mathrm{IFN}-\gamma^{+}$

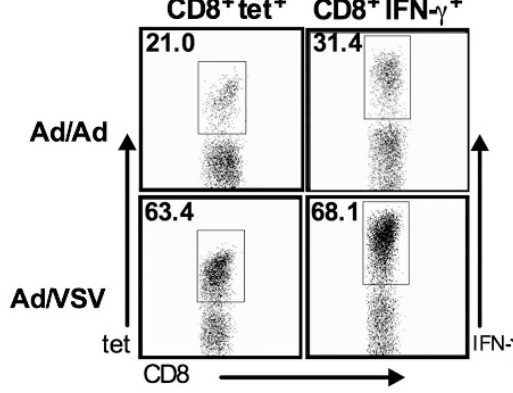
$\mathrm{CD}^{+}$tet $^{+}$
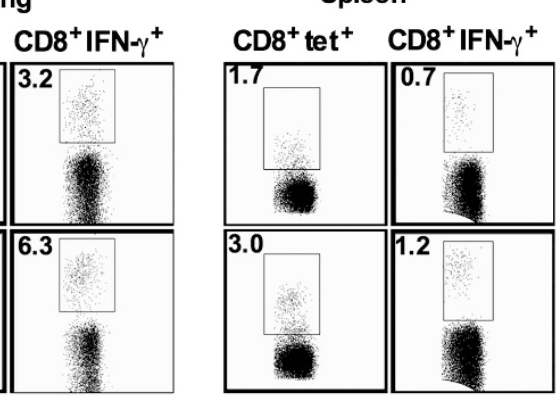

c
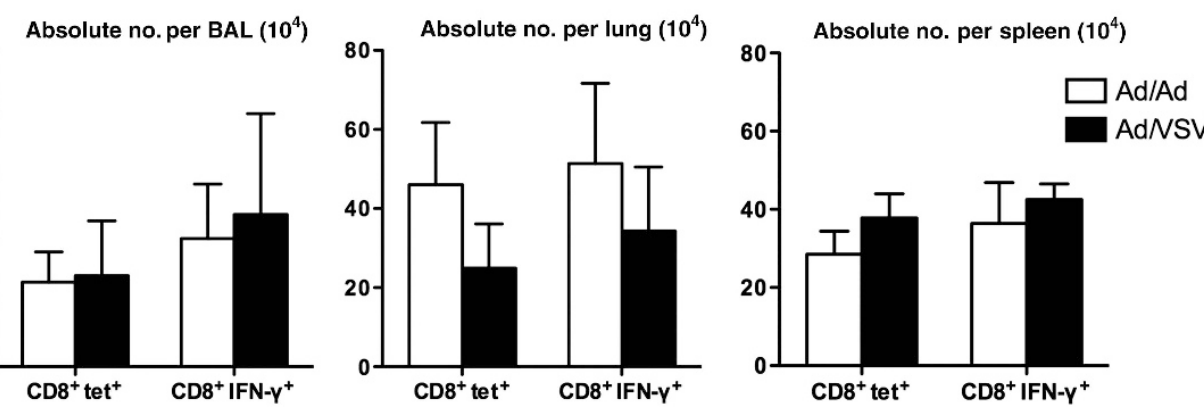

Figure 1 Homologous and heterologous respiratory mucosal boost immunizations elicit comparable levels of antigen-specific T-cell responses in the lung and systemic lymphoid tissue. (a) Experimental schema. (b) At 2 weeks postboost immunization, bronchoalveolar lavage (BAL), lung, and spleen cells were isolated and subject to CD8 T-cell tetramer (tet) immunostaining or interferon (IFN)- $\gamma$ intracellular cytokine immunostaining (ICCS) $\left(\mathrm{CD} 8^{+} \mathrm{IFN}-\gamma^{+}\right)$. Representative dotplots are shown. (c) Absolute numbers of tetramer ${ }^{+}\left(\mathrm{CD}^{+}\right.$tet $\left.^{+}\right)$or IFN- $\gamma^{+}\left(\mathrm{CD} 8^{+}\right.$IFN- $\left.\gamma^{+}\right) \mathrm{CD} 8 \mathrm{~T}$ cells in BAL, lung, and spleen. The data are expressed as mean \pm s.e.m. of cell numbers from three to four mice per group, representative of two independent experiments. AdAg85A, recombinant adenovirus expressing an immunodominant M.tb Ag Ag85A; i.m., intramuscularly; i.n., intranasally; VSVAg85A, vesicular stomatitis virus-vectored vaccine expressing Ag85A. 
a
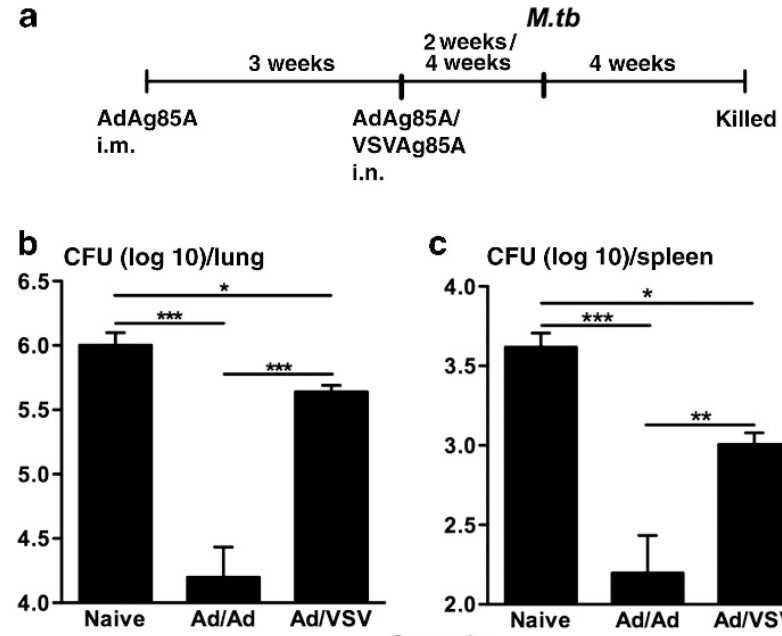

C CFU $(\log 10) /$ spleen

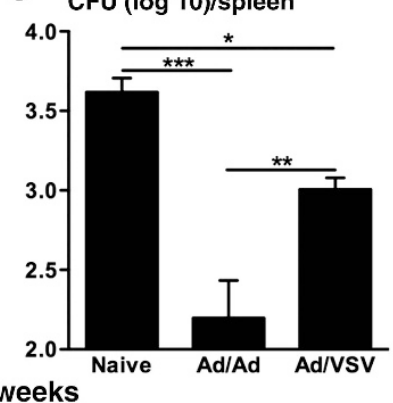

d CFU (log 10)/lung

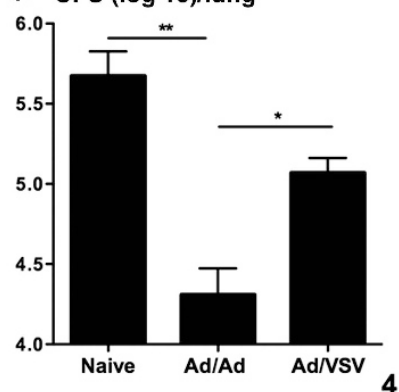

4 weeks

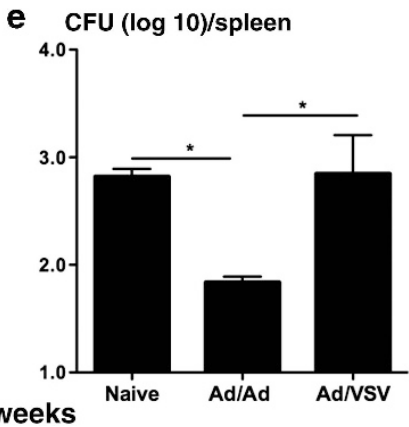

Figure 2 Homologous and heterologous respiratory mucosal boost immunizations lead to markedly different immune-protective outcomes. (a) Experimental schema. Mice were Mycobacterium tuberculosis (M.tb)challenged (b and c) 2 weeks or (d and e) 4 weeks after intranasal (i.n.) boost immunization and killed at 4 weeks postchallenge. Mycobacterial counts in the lungs and spleens were evaluated using colony-forming assay. Results are expressed as mean \pm s.e.m. of bacterial forming units (CFU) from five to six mice per group. AdAg85A, recombinant adenovirus expressing an immunodominant M.tb Ag Ag85A; i.m., intramuscularly; VSVAg85A, vesicular stomatitis virus-vectored vaccine expressing Ag85A.

levels of infection were seen in the spleen of Ad/VSV animals (Figure 2c). To examine whether the inferior protection in $\mathrm{Ad} /$ VSV animals was only true of the 2-week interval between the point of VSV boosting and M.tb challenge, the groups of mice were also challenged at 4 weeks postboosting (Figure 2a). The mice immunized by Ad/Ad remained well protected both in the lung and spleen, compared with naive animals (Figure 2d). In contrast, the mice immunized by Ad/VSV displayed only a modestly increased level of protection in the lung and little improved protection in the spleen (Figure 2e). Given our previous finding that VSVAg85A alone, when used as a standalone mucosal vaccine, provided little protection in the lung (challenged at 4 weeks post-VSV), ${ }^{30}$ the current data suggest that Ad/VSV mice had moderately improved protection, but it is still markedly inferior to that by $\mathrm{Ad} / \mathrm{Ad}$. These data together indicate that despite the comparable levels of M.tb Agspecific T-cell responses by Ad and VSV mucosal boost immunizations, Ad boost immunization provides much better protection than VSV boost immunization.
Homologous Ad respiratory mucosal boost immunization leads to much enhanced innate immune activation in the lung compared with heterologous VSV boost immunization

It is increasingly realized that effective control of $M$.t $b$ infection requires not only the properly activated $\mathrm{T}$ cells but also the responsive/activatible innate $M . t b$ phagocytic cell populations (macrophages and dendritic cells). ${ }^{14,21-24,31}$ As we observed the comparable levels of activated T cells in the lung of $\mathrm{Ad} / \mathrm{Ad}$ and Ad/VSV animals, we postulated that the mechanism for much inferior immune protection mediated by Ad/VSV heterologous boost immunization could lie on the side of innate phagocytic cells. Thus, to begin dissecting the mechanisms underlying the differential levels of immune protection by homologous and heterologous boost immunizations, we first evaluated the levels of interleukin (IL)-12 and IL-10 in the lung following boost immunization before and after mycobacterial challenge. IL-12 is a classic proimmune cytokine and was shown to be required for the production of IFN- $\gamma$, a critical macrophage-activating cytokine, ${ }^{32}$ from mycobacterium-infected macrophages. ${ }^{33,34}$ On the other hand, IL-10 is a potent immune-suppressive cytokine shown to inhibit antimycobacterial activities of macrophages and dendritic cells. ${ }^{35}$ To this end, mice were prime- and boost-immunized as described in Figure 2a. Groups of animals were killed at 2 weeks after boost immunization but without M.tb challenge (Ad/Ad; Ad/ VSV) or at 2 weeks after challenge (Ad/Ad/Mtb; Ad/VSV/ $\mathrm{Mtb})$. The BAL fluids obtained from these animals were subjected to cytokine analysis. Before M.tb challenge, significantly higher levels of IL-12 were detected in the BAL fluids of Ad/Ad animals than in Ad/VSV animals (Figure 3a). After challenge, the levels of IL-12 further increased in the lung of $\mathrm{Ad} / \mathrm{Ad}$ animals, while they hardly increased in the lung of Ad/VSV animals, resulting in a 400 times difference in IL-12 levels between $\mathrm{Ad} / \mathrm{Ad}$ and $\mathrm{Ad} / \mathrm{VSV}$ animals (Figure 3a). Consistent with highly induced IL-12 production by mycobacterial exposure in Ad/Ad animals, IFN- $\gamma$ levels were increased in $\mathrm{Ad} / \mathrm{Ad}$, but not $\mathrm{Ad} / \mathrm{VSV}$, animals (data not shown). On the other hand, the levels of IL-10 were found to be markedly lower, before and after M.tb challenge, in the lung of $\mathrm{Ad} / \mathrm{Ad}$ animals than in $\mathrm{Ad} / \mathrm{VSV}$ animals (Figure 3b). By intracellular cytokine staining, we found $\mathrm{CD} 11 \mathrm{c}^{+}$phagocytic cells to be the main cellular source of IL-12 and IL-10 (data not shown) and the relative frequencies of these cells correlated with the relative contents of IL-12/IL-10 proteins detected in the lung of $\mathrm{Ad} / \mathrm{Ad}$ and Ad/VSV animals. These data together indicate an inverse relationship in the levels of IL-12 and IL-10 in the lungs of Ad and VSV boost-immunized animals, and that Ad boost immunization elicited much enhanced innate immune activation in the lung.

Considering the important role of IL-12 and IL-10 in the regulation of $M . t b$ phagocyte activation, the local production of these cytokines differentially regulated by Ad and VSV boost immunizations could have impacted the activation and antimycobacterial functionality of phagocytes in the lung. To examine the activation status of phagocytes in the lung, we 
first characterized the phenotype of phagocytic cell populations in the lung before and after mycobacterial challenge of animals immunized with homologous and heterologous regimes. The phagocytic macrophage and dendritic cell populations are broadly defined by their relative expression of complement
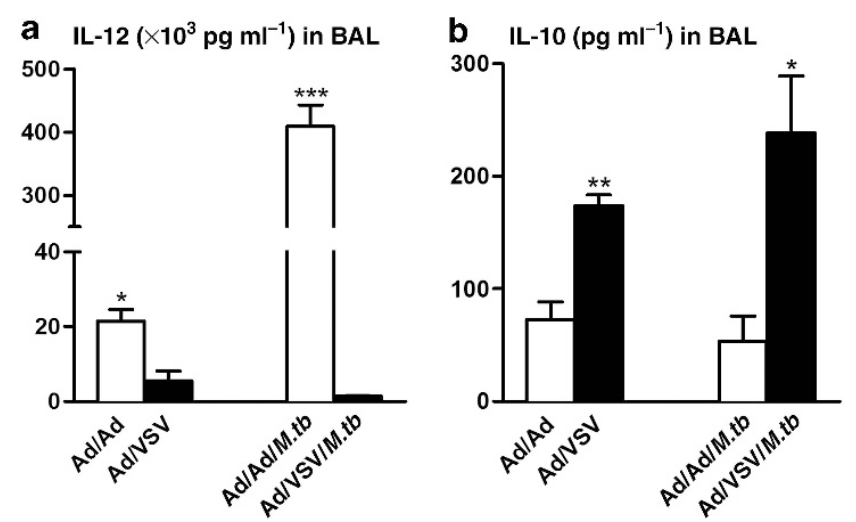

Figure 3 Differential innate immune cytokine responses in the lung following homologous and heterologous respiratory mucosal boost immunizations. Mice were prime- and boost-immunized as described in Figure 2a. Groups of animals were killed at 2 weeks after boost immunization but without Mycobacterium tuberculosis (M.tb) challenge (Ad/Ad; Ad/VSV) or at 2 weeks after M.tbchallenge (Ad/Ad/M. tb; Ad/VSV/ M. $t b$ ). The protein levels of cytokines (a) interleukin (IL)-12 and (b) IL-10 were measured by enzyme-linked immunosorbent assay (ELISA) in the bronchoalveolar lavage (BAL) fluids. Results are expressed as mean \pm s.e.m. of cytokine levels from three mice per group, representative of two independent experiments. Ad, adenovirus; VSV, vesicular stomatitis virus.

Figure 4 Differentially increased frequencies of CD11c ${ }^{+}$phagocytic cell populations in the lung following homologous and heterologous respiratory mucosal boost immunizations prior and subsequent to Mycobacterium tuberculosis (M.tb) challenge. Mice were prime- and boost-immunized as described in Figure 1a. At 2 weeks postboost immunization, isolated lung cells were immunostained for CD11c, CD11b, and major histocompatibility complex (MHC) class II surface markers. (a) The frequencies of $\mathrm{CD} 11 \mathrm{c}^{+} \mathrm{CD} 11 \mathrm{~b}^{+/-}$and $\mathrm{CD} 11 \mathrm{c}^{-} \mathrm{CD} 11 \mathrm{~b}^{+}$cell populations were determined by fluorescence-activated cell sorter (FACS). Representative contour plots are shown and the bar graph represents the mean \pm s.e.m. of frequencies of $C D 11 c^{+} C D 11 b^{+/-}$and CD $11 c^{-}$CD11 $b^{+}$cells from three to four mice per group. (b and $\left.\mathbf{d}\right)$ The frequencies of $\mathrm{CD} 11 \mathrm{c}^{+} \mathrm{CD} 11 \mathrm{~b}^{+/-}$and $\mathrm{CD} 11 \mathrm{c}^{-} \mathrm{CD} 11 \mathrm{~b}^{+}$cell populations that express MHC class II molecule. Numbers in histograms represent the mean \pm s.e.m. of frequencies from three to four mice per group. (c and $\mathbf{e}$ ) The level of MHC class II expression assessed as the mean fluorescence intensity (MFI) of (c) $\mathrm{CD} 11 \mathrm{c}^{+} \mathrm{CD} 11 \mathrm{~b}^{+/-}$and (d) $\mathrm{CD} 11 \mathrm{c}^{-} \mathrm{CD} 11 \mathrm{~b}^{+}$populations. In separate experiments, mice were prime- and boost-immunized, and M.tb challenged as described in Figure 2a. At 2 weeks postchallenge, isolated lung cells were immunostained for CD11C, CD11b, and MHC class II surface markers. (f) The frequencies of $\mathrm{CD} 11 \mathrm{c}^{+} \mathrm{CD} 11 \mathrm{~b}^{+/-}$and $\mathrm{CD} 11 \mathrm{c}^{-} \mathrm{CD} 11 \mathrm{~b}^{+}$cell populations were determined by FACS. Representative contour plots are shown and the bar graph represents the mean \pm s.e.m. of frequencies of $\mathrm{CD} 11 \mathrm{c}^{+} \mathrm{CD} 11 \mathrm{~b}^{+/-}$and $\mathrm{CD} 11 \mathrm{c}^{-} \mathrm{CD} 11 \mathrm{~b}^{+}$cells from three to four mice per group. ( $g$ and i) The frequencies of $\mathrm{CD} 11 \mathrm{c}^{+} \mathrm{CD} 11 \mathrm{~b}^{+/-}$and CD $11 c^{-}{ }^{-} D 11 b^{+}$cell populations that express MHC class II molecule. Numbers in histograms represent the mean \pm s.e.m. of frequencies from three to four mice per group. (h and $\mathbf{j})$ The level of MHC class II expression assessed as the MFI of (h) CD11 ${ }^{+}$CD11 $b^{+/-}$and (j) CD11 ${ }^{-}$CD11 $b^{+}$ populations. Results are expressed as mean \pm s.e.m. of MFI from three to four mice per group. The above data are representative of three independent experiments. Ad, adenovirus; VSV, vesicular stomatitis virus. receptors, CR3 (CD11b/CD18) and CR4 (CD11c/CD18), and major histocompatibility complex (MHC) class II molecules. ${ }^{36}$ Immunization and mycobacterial challenge were performed as described in Figure 3, and the mononuclear cells were obtained from lung of these animals and subjected to CD11b, CD11c, and MHC class II immunostaining and fluorescence-activated cell sorter (FACS) analysis. Before M.tb challenge, Ad/Ad animals had significantly increased frequencies of $\mathrm{CD}_{11 \mathrm{c}^{+}} \mathrm{CD} 11 \mathrm{~b}^{+/-}$cell population in the lung compared with Ad/VSV animals (Figure 4a). However, the frequencies of

a

Before M.tb challenge

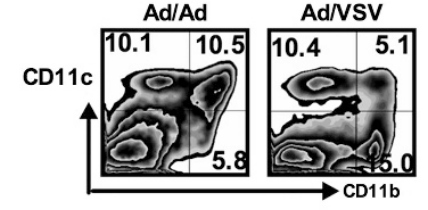

b

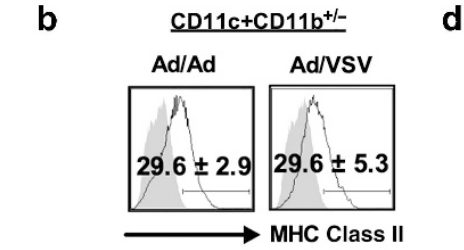

d

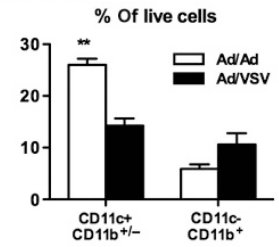

CD11C-CD11b ${ }^{+}$

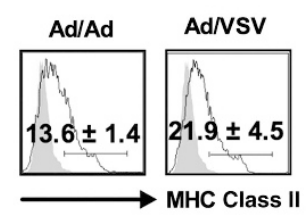

C
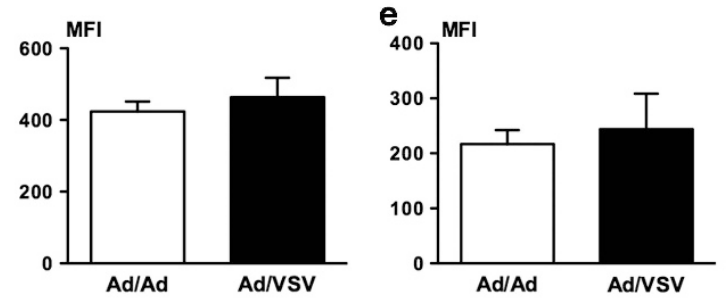

f

After M.tb challenge
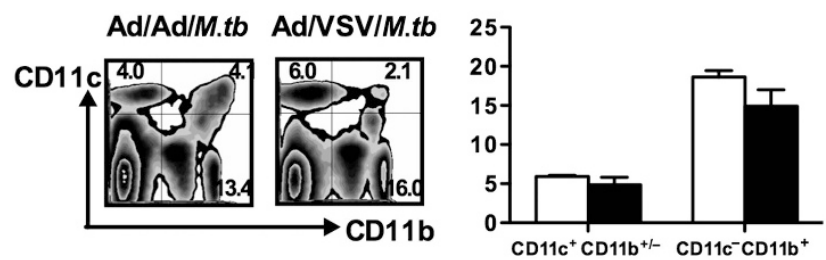

g

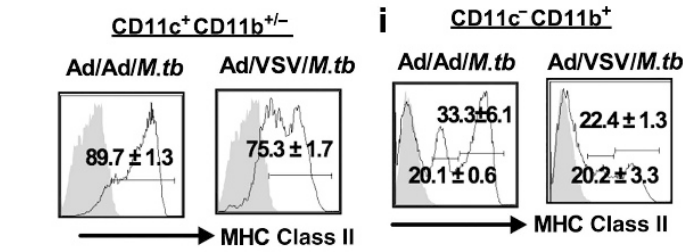

h
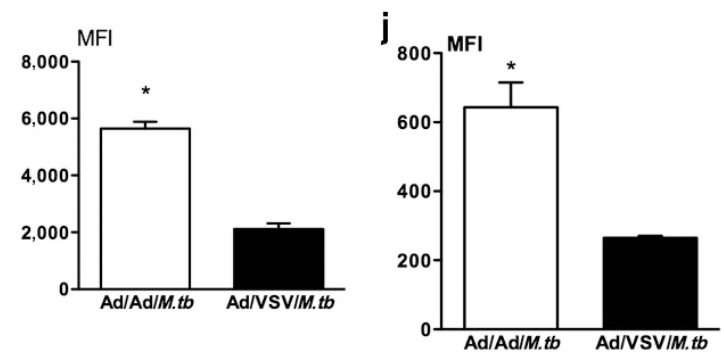
$\mathrm{CD}_{11 \mathrm{c}^{-}} \mathrm{CD}_{11 \mathrm{~b}^{+}}$cell population were comparable in both groups of animals. Furthermore, the level of MHC class II expression on these cell populations was examined as a means of calibrating the level of activation. We found that the frequencies of MHC class II-expressing $\mathrm{CD} 11 \mathrm{c}^{+} \mathrm{CD} 11 \mathrm{~b}^{+/-}$ and $\mathrm{CD} 11 \mathrm{c}^{-} \mathrm{CD}_{11 \mathrm{~b}^{+}}$cells (Figure $\mathbf{4 b}, \mathbf{d}$ ) and the intensity of MHC class II expression assessed as mean fluorescence intensity (MFI) (Figure 4c, e) were comparable in $\mathrm{Ad} / \mathrm{Ad}$ and Ad/VSV animals before mycobacterial challenge. On the contrary, after mycobacterial challenge, although the frequencies of $\mathrm{CD}_{11 \mathrm{c}^{+}} \mathrm{CD} 11 \mathrm{~b}^{+/-}$and $\mathrm{CD} 11 \mathrm{c}^{-} \mathrm{CD} 11 \mathrm{~b}^{+}$ cells in the lung were highly comparable in $\mathrm{Ad} / \mathrm{Ad}$ and $\mathrm{Ad} / \mathrm{VSV}$ animals (Figure 4f), there were significantly greater frequencies of $\mathrm{MHC}$ class II-expressing $\mathrm{CD} 11 \mathrm{c}^{+} \mathrm{CD} 11 \mathrm{~b}^{+/-}$and $\mathrm{CD} 11 \mathrm{c}^{-} \mathrm{CD}_{11 \mathrm{~b}^{+}}$cells in the lung of $\mathrm{Ad} / \mathrm{Ad}$ animals than in Ad/VSV animals (Figure 4g, i). Furthermore, although mycobacterial challenge increased the overall intensity (MFI) of MHC class II expression on the cells in both $\mathrm{Ad} / \mathrm{Ad}$ and $\mathrm{Ad} /$ VSV animals (Figure $4 \mathbf{h}, \mathbf{j}$ ) compared with those before challenge (Figure $\mathbf{4 c}, \mathbf{e}$ ), it was markedly higher on the $\mathrm{CD} 11 \mathrm{c}^{+} \mathrm{CD} 11 \mathrm{~b}^{+/-}$and $\mathrm{CD} 11 \mathrm{c}^{-} \mathrm{CD} 11 \mathrm{~b}^{+}$cells in the lung of $\mathrm{Ad} / \mathrm{Ad}$ animals (Figure $\mathbf{4 h}, \mathbf{j}$ ). The above data together suggest that consistent with its much greater immune protection, Ad mucosal boost immunization enhances overall innate immune activation in the lung, whereas VSV boost immunization leads to a relatively depressed innate immune phenotype in the lung, especially after mycobacterial exposure.

Lung innate phagocytic cells activated by homologous Ad respiratory mucosal boost immunization can better control TB infection than those by heterologous VSV boost immunization

Having found out that homologous Ad boost immunization regimen elicits a more activated innate immune microenvironment in the lung with much activated phagocytic cells, compared with heterologous VSV immunization, we next compared antimycobacterial status in these phagocytic cell populations. To this end, mice were prime- and boostimmunized as depicted in Figure 1a and both $\mathrm{CD}_{11 \mathrm{C}^{+}}$ $\left(\mathrm{CD} 11 \mathrm{c}^{+} \mathrm{CD} 11 \mathrm{~b}^{+/-}\right)$and $\mathrm{CD}^{+1} \mathrm{~b}^{+}\left(\mathrm{CD} 11 \mathrm{c}^{-} \mathrm{CD} 11 \mathrm{~b}^{+}\right)$ phagocytic cell populations were purified from total lung mononuclear cells. These cell populations were then infected with M.tb in vitro. The level of antimycobacterial status in these cells was determined by intracellular bacterial counts (colonyforming unit (CFU)). We found that lung $\mathrm{CD} 11 \mathrm{c}^{+} \mathrm{CD} 11 \mathrm{~b}^{+/-}$ cells from $\mathrm{Ad} / \mathrm{Ad}$ animals much better controlled mycobacterial infection than Ad/VSV counterparts (Figure 5a). By comparison, the lung CD11 ${ }^{-} \mathrm{CD}_{11} \mathrm{~b}^{+}$cells from both $\mathrm{Ad} / \mathrm{Ad}$ and Ad/VSV animals had similar levels of mycobacterial counts (Figure $\mathbf{5 b}$ ).

To examine the ability of these phagocytic cell populations to control mycobacterial infection in vivo, mice were prime- and boost-immunized and M.tb-challenged as in Figure 2a, except that at 2 weeks after challenge, lung $\mathrm{CD}_{11} \mathrm{c}^{+} \mathrm{CD} 11 \mathrm{~b}^{+/-}$ and $\mathrm{CD} 11 \mathrm{c}^{-} \mathrm{CD} 11 \mathrm{~b}^{+}$cells were purified and intracellular mycobacterial counts were determined. Consistent with the in vitro phagocytic killing
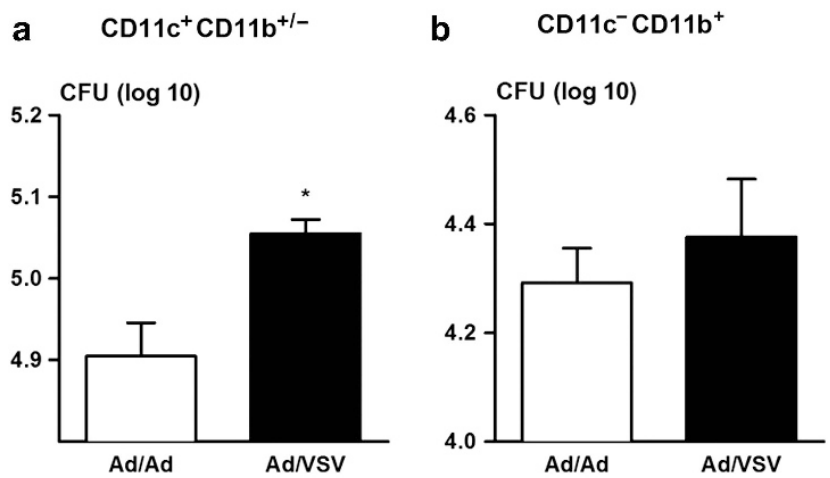

in vivo phagocytic killing
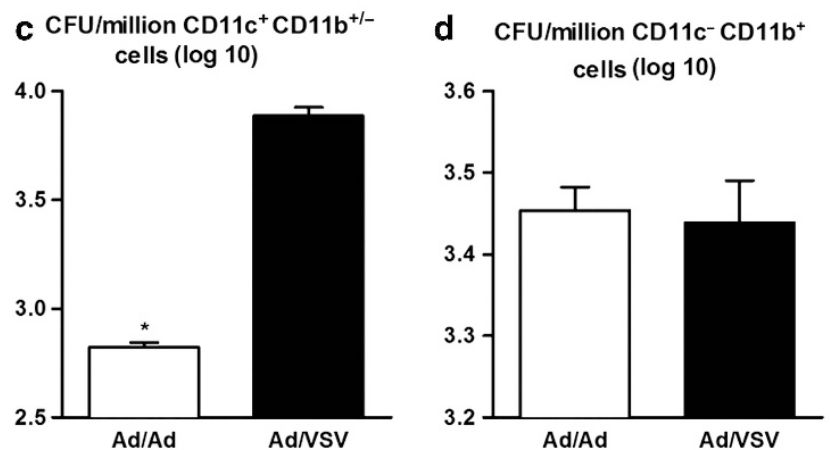

Figure 5 Differential control of mycobacterial infection in phagocytic cell populations following homologous and heterologous respiratory mucosal boost immunizations. ( $(\mathbf{a}$ and $\mathbf{b}$ ) Mice were prime- and boostimmunized as depicted in Figure 1a and both lung $\mathrm{CD} 11 \mathrm{c}^{+} \mathrm{CD} 11 \mathrm{~b}^{+/-}$and CD11c ${ }^{-}$CD11 ${ }^{+}$phagocytic cell populations were purified and then infected in vitro with Mycobacterium tuberculosis (M.tb). The level of antimycobacterial status in these cells was examined by determining intracellular bacterial counts (colony-forming unit (CFU)) at $24 \mathrm{~h}$ postinfection. Results are expressed as the mean \pm s.e.m. of CFU per $10^{5}$ cells of triplicate samples, representative of two independent experiments. (c and d) Mice were prime- and boost-immunized and $M$.tb-challenged in vivo as in Figure 2a, except that at 2 weeks after challenge, $C D 11 c^{+} C D 11 b^{+1-}$ and $\mathrm{CD} 11 \mathrm{c}^{-} \mathrm{CD} 11 \mathrm{~b}^{+}$cell populations were purified and intracellular mycobacterial counts were determined. Results are expressed as the mean \pm s.e.m. of CFU per $10^{6}$ cells of triplicate samples from 4 to 6 animals per group. Ad, adenovirus; VSV, vesicular stomatitis virus.

in vitro observations (Figure 5a, b), CD11 ${ }^{+} \mathrm{CD}_{11} \mathrm{~b}^{+/-}$cells in the lung of infected Ad/Ad animals contained much fewer viable bacteria ( $>1 \log$ lower) than Ad/VSV counterparts (Figure 5c), whereas $\mathrm{CD}_{11 \mathrm{c}^{-}} \mathrm{CD}_{11 \mathrm{~b}^{+}}$cells from both infected $\mathrm{Ad} / \mathrm{Ad}$ and $\mathrm{Ad} / \mathrm{VSV}$ animals had comparable numbers of bacteria (Figure 5d). The above data together indicate that compared with VSV boost immunization, Ad boost immunization leads to the generation of highly activated innate phagocytic cells, particularly $\mathrm{CD}_{11 c^{+}} \mathrm{CD}_{11 b^{+/-}}$ population, which are more capable of controlling M.tb infection in the lung.

\section{Enhanced anti-TB activities of lung phagocytic cells activated by homologous Ad respiratory mucosal boost immunization are mediated by nitric oxide}

We next further determined the mechanisms for differential mycobacterial control in lung $\mathrm{CD} 11 \mathrm{c}^{+} \mathrm{CD} 11 \mathrm{~b}^{+/-}$phagocytic 


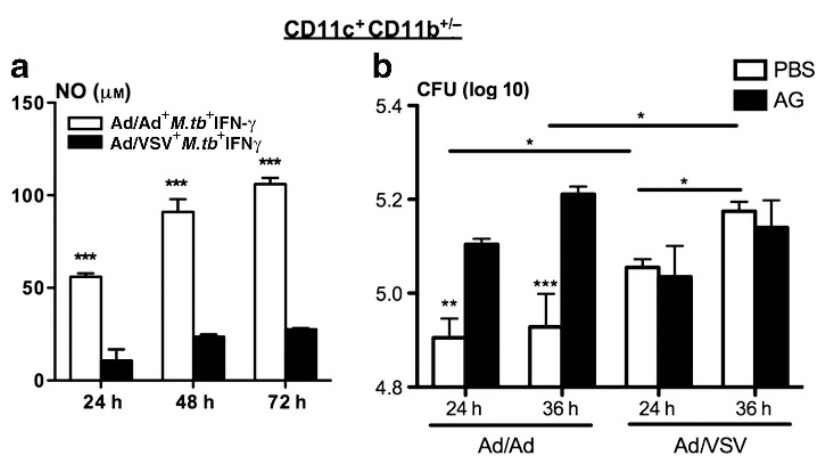

Figure 6 Role of nitric oxide (NO) in differential control of mycobacterial infection in $\mathrm{CD}_{11 \mathrm{c}^{+}}$phagocytic cells following homologous and heterologous respiratory mucosal boost immunizations. (a) Mice were prime- and boost-immunized as depicted in Figure 1a and lung $\mathrm{CD} 11 \mathrm{c}^{+} \mathrm{CD} 11 \mathrm{~b}^{+/-}$phagocytic cell populations were purified and infected with Mycobacterium tuberculosis (M.tb) in the presence of recombinant interferon (IFN)- $\gamma$ and their NO production was measured in supernatants at indicated times. Results are expressed as the mean \pm s.e.m. of NO levels per $10^{6}$ cells of triplicate samples from 3 to 4 animals per group, representative of two independent experiments. (b) Mice were prime- and boost-immunized as depicted in Figure 1a and lung $\mathrm{CD}_{11 \mathrm{c}^{+}} \mathrm{CD}_{11 \mathrm{~b}^{+/-}}$phagocytic cell populations were purified from $\mathrm{Ad} / \mathrm{Ad}$ and Ad/VSV animals. These cells were infected and treated as for (a) in the absence or the presence of NO inhibitor aminoguanidine. At various times of incubation, equal numbers of cells were lysed and intracellular bacterial counts were determined. Results are expressed as the mean \pm s.e.m. of colony-forming unit (CFU) per $10^{6}$ cells of triplicate samples from 4 to 6 animals per group, representative of two independent experiments. Ad, adenovirus; AG, aminoguanidine; PBS, phosphate-buffered saline; VSV, vesicular stomatitis virus.

cell population by homologous Ad and heterologous VSV boost immunization regimens. As effective control of intracellular mycobaterial infection requires production of nitric oxide $(\mathrm{NO}),{ }^{14,23}$ we examined the ability of lung $\mathrm{CD} 11 \mathrm{c}^{+} \mathrm{CD} 11 \mathrm{~b}^{+/-}$ cells to produce $\mathrm{NO}$ in response to mycobacterial infection. Thus, $\mathrm{CD} 11 \mathrm{c}^{+} \mathrm{CD} 11 \mathrm{~b}^{+/-}$cells purified from lungs of $\mathrm{Ad} / \mathrm{Ad}$ and Ad/VSV animals were cultured in the presence of $M . t b$ and recombinant IFN- $\gamma$, and $\mathrm{NO}$ production was measured in the culture supernatant at various times after initial infection. Indeed, at all of the time points examined, the cells from $\mathrm{Ad} / \mathrm{Ad}$ animals produced more than fivefold increased amounts of NO compared with the cells from Ad/VSV animals (Figure 6a). To further examine whether increased NO production accounted for significantly enhanced control of mycobacterial infection by the lung $\mathrm{CD} 11 \mathrm{c}^{+} \mathrm{CD} 11 \mathrm{~b}^{+/-}$cells of $\mathrm{Ad} / \mathrm{Ad}$ animals, an inducible NO synthase inhibitor, aminoguanidine (AG) was added to the culture of infected $\mathrm{CD} 11 \mathrm{c}^{+} \mathrm{CD} 11 \mathrm{~b}^{+/-}$cells from Ad/Ad animals, and the intracellular mycobacterial counts were determined at various times. Indeed, compared with the control (Ad/Ad), inhibition of NO production (Ad/Ad (AG)) resulted in the loss of enhanced control of mycobacterial infection by the $\mathrm{CD} 11 \mathrm{c}^{+} \mathrm{CD} 11 \mathrm{~b}^{+/-}$population (Figure $6 \mathbf{b}$ ). By comparison, inhibition of $\mathrm{NO}$ had a minimum effect on the level of infection in the $\mathrm{CD} 11 \mathrm{c}^{+} \mathrm{CD} 11 \mathrm{~b}^{+/-}$cells from $\mathrm{Ad} /$ VSV animals. These data suggest that compared with VSV mucosal boost immunization, Ad boost immunization elicits a more activated innate microenvironment in the lung with highly activated phagocytic cells, particularly $\mathrm{CD} 11 \mathrm{c}^{+}$ phagocytes, capable of enhanced antimycobacterial activities via increased production of NO.

\section{A critical role of IL-12 in determining the activation status of anti-TB innate phagocytes and immune protective outcomes by mucosal boost immunization}

Having fully established differentially activated phagocytic cells, particularly the $\mathrm{CD}_{11 \mathrm{c}^{+}} \mathrm{CD} 11 \mathrm{~b}^{+/-}$population, by homologous and heterologous boost immunizations, and its relationship to anti-TB immune-protective outcomes, we set out to investigate the underlying molecular mechanisms. As we have detected significantly impaired IL-12 production in the lung of Ad/VSV animals (Figure 3a) and this cytokine is critical to phagocyte activation via inducing IFN- $\gamma$, tumor necrosis factor- $\alpha$, and NO production, ${ }^{33,34,37}$ we further determined the role of IL-12 in differential regulation of phagocytic cell activation by $\mathrm{Ad} / \mathrm{Ad}$ and $\mathrm{Ad} / \mathrm{VSV}$ immunizations. Using lung $\mathrm{CD}_{11 \mathrm{c}^{+}} \mathrm{CD}_{11} \mathrm{~b}^{+/-}$cells purified from $\mathrm{Ad} / \mathrm{Ad}$ and $\mathrm{Ad} / \mathrm{VSV}$ animals, we first compared IL-12 production by these cells upon $M . t b$ infection in the presence or absence of recombinant IFN- $\gamma$. We found that infected CD11 $\mathrm{c}^{+} \mathrm{CD} 11 \mathrm{~b}^{+/-}$cells from Ad/VSV animals released much less IL-12 protein compared with $\mathrm{Ad} / \mathrm{Ad}$ counterparts in the absence of exogenous recombinant IFN- $\gamma$, and that exogenous IFN- $\gamma$ only partially restored their IL-12 production (Figure 7a). Of note, exogenous supply of IFN- $\gamma$ did not further enhance IL-12 production by $\mathrm{Ad} / \mathrm{Ad} \mathrm{CD} 11 \mathrm{c}^{+} \mathrm{CD} 11 \mathrm{~b}^{+/-}$cells (Figure $7 \mathbf{a}$ ). Next, we examined the relationship of IL-12 with NO production by this cell population. Consistent with the earlier observation (Figure 6a), $\mathrm{CD} 11 \mathrm{c}^{+} \mathrm{CD} 11 \mathrm{~b}^{+/-}$cells from Ad/VSV animals released significantly less NO than Ad/ Ad counterparts (black bars in Figure 7b). However, exogenous supply of recombinant IL-12 fully restored the levels of NO release by $\mathrm{Ad} / \mathrm{VSV}$ cells, whereas it only minimally further increased NO production by the Ad/Ad counterparts (Figure $7 \mathbf{b}$ ). These data suggest that IL-12 production by $\mathrm{CD} 11 \mathrm{c}^{+} \mathrm{CD} 11 \mathrm{~b}^{+/-}$cells is critical to their NO production and that impaired $\mathrm{IL}-12$ responses in $\mathrm{CD} 11 \mathrm{c}^{+} \mathrm{CD} 11 \mathrm{~b}^{+/-}$ phagocytes in the lung of VSV mucosal boost-immunized animals account for reduced NO production by these cells.

Thus, given the critical role of IL-12 in the activation of phagocytic cells, the ultimate anti-M.tb effectors, ${ }^{14,23}$ we investigated the relationship of severely impaired IL-12 production to poorly enhanced anti-M.tb immune protection seen in Ad/VSV heterologous boost-immunized animals (Figure 2). To this end, mice were immunized using $\mathrm{Ad} /$ Ad and Ad/VSV regimens (Figure 7c) and a group of animals were administered via the airways with recombinant IL-12 protein at 5, 12, and $48 \mathrm{~h}$ postboost immunization ( $\mathrm{Ad} /$ $\mathrm{VSV}^{+}$IL-12). The mice were then infected with M.tb 2 weeks after boost immunization and killed for determining mycobacterial burden in the lung 2 weeks after challenge (Figure 7c). Consistent with our earlier observation (Figure 2), protection in the lung by Ad/VSV heterologous immunization was much inferior to that by $\mathrm{Ad} / \mathrm{Ad}$ homologous immunization (Ad/Ad vs. Ad/VSV; Figure 7d). However, lung deliveries of 
recombinant IL-12 protein markedly improved the otherwise poor protection in the lung of $\mathrm{Ad} / \mathrm{VSV}$ animals $\left(\mathrm{Ad} / \mathrm{VSV}^{+} \mathrm{IL}-\right.$ 12; Figure 7d). These observations together suggest that in spite of similarly activated $\mathrm{T}$-cell responses in the lung (Figure 1), Ad
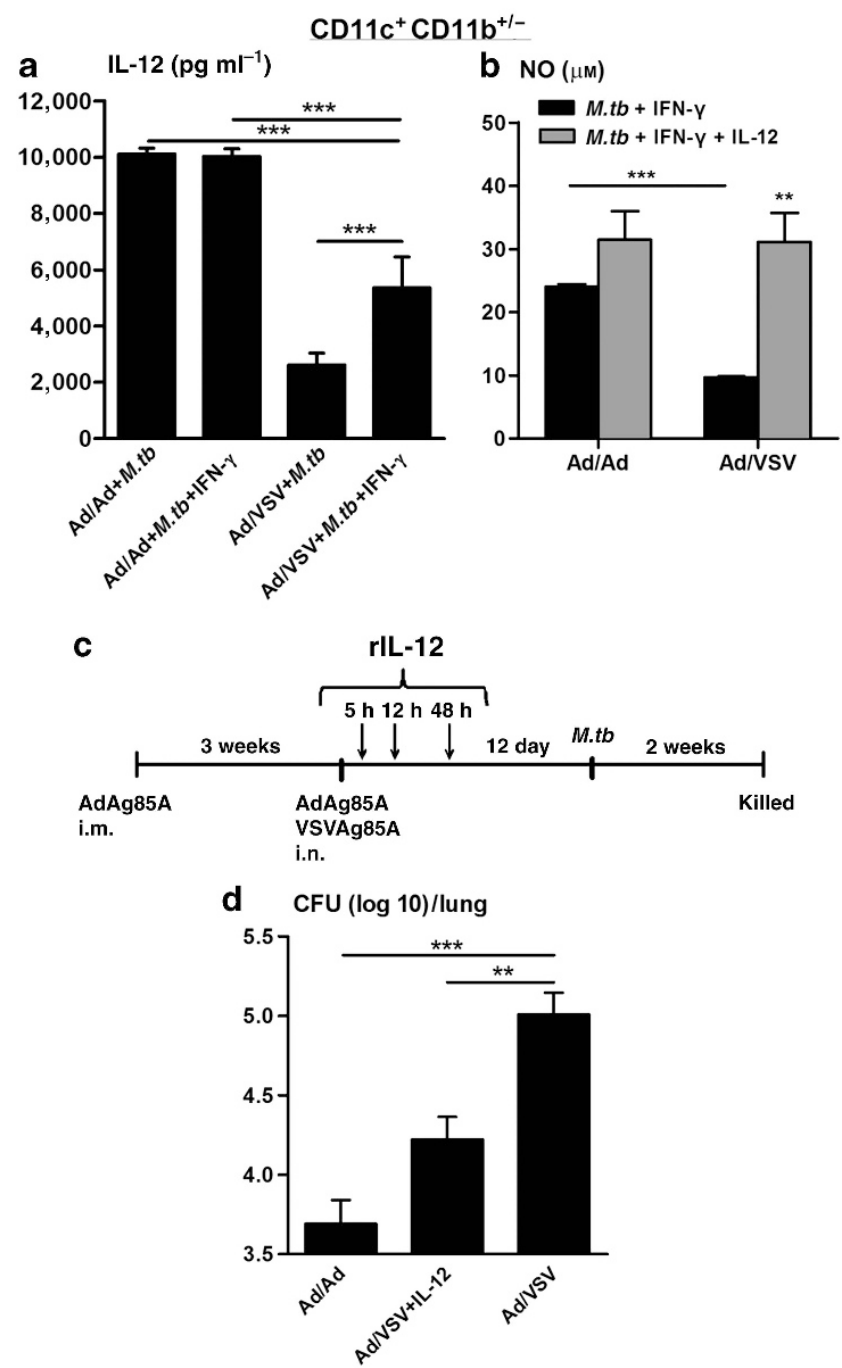

Figure 7 Critical role of interleukin (IL)-12 in the activation of innate phagocytic cell populations and antituberculosis (TB) host defense following homologous and heterologous respiratory mucosal boost immunizations. (a) Mice were prime- and boost-immunized as depicted in Figure $1 \mathrm{a}$ and lung $\mathrm{CD} 11 \mathrm{c}^{+} \mathrm{CD} 11 \mathrm{~b}^{+/-}$phagocytic cell populations were purified and infected with Mycobacterium tuberculosis (M.tb). Cells were cultured for $48 \mathrm{~h}$ with or without recombinant interferon (IFN)- $\gamma$. Production of IL-12 protein was determined in the culture supernatants by enzymelinked immunosorbent assay (ELISA). Results are expressed as the mean \pm s.e.m. of IL-12 levels per $10^{6}$ cells of triplicate samples from three to four animals per group, representative of two independent experiments. (b) Mice were treated and the cells isolated as for a. The cells were infected with $M$.tb and cultured in the presence of recombinant IFN- $\gamma$ with or without recombinant IL-12. Nitric oxide (NO) production was measured in culture supernatants. Results are expressed as the mean \pm s.e.m. of $\mathrm{NO}$ levels per $10^{6}$ cells of triplicate samples from three to four animals per group, representative of two independent experiments. (c) Experimental schema for d. (d) Sham- and IL-12-treated infected mice were killed at 2 weeks post-M.tb challenge and mycobacterial counts in lungs were determined. Results are expressed as the mean \pm s.e.m. of colony-forming unit (CFU) from 4 to 5 animals per group. Ad, adenovirus; i.m., intramuscularly; i.n., intranasally; VSV, vesicular stomatitis virus. and VSV mucosal boost immunizations have a profound effect on anti-TB immune-protective outcomes in the lung via differentially imprinting innate immune cells and that IL-12 represents an important molecular player in dictating the property of such anti-TB innate immune cells.

Type 1 IFN- $\beta$ is a critical molecule suppressing IL-12 responses, innate phagocyte activation, and anti-TB activities following mucosal boost immunization

Mounting evidence suggests that type 1 IFN- $\alpha / \beta$ can negatively regulate IL-12 responses in certain models of intracellular infection. ${ }^{38-40}$ This prompted us to address the question whether suppressed IL-12 responses and anti-M.tb innate phagocytic cells by VSV mucosal boost immunization resulted from heightened type 1 IFN responses to VSV booster vaccine exposure in the lung. To approach this issue, animals were $\mathrm{Ad} /$ Ad- and Ad/VSV-immunized as described in Figure 1a, and $24 \mathrm{~h}$ after boost immunization, BAL fluids were collected from these animals and measured for the content of IFN- $\beta$ by enzyme-linked immunosorbent assay (ELISA). This time point was chosen because viral clearance occurs within $48 \mathrm{~h}$ after infection in the lung. Indeed, while we found that Ad boosting induced hardly detectable IFN- $\beta$ production, VSV boosting elicited very high levels of IFN- $\beta$ production in the lung, which was at least 1,000 times higher than in the lung of $\mathrm{Ad} / \mathrm{Ad}$ animals (Figure 8a). These results strongly suggest IFN- $\beta$ to be a key upstream molecule involved in regulating innate IL-12 responses and subsequent innate immune cell activation.

To examine the relationship between IFN- $\beta$ and antimycobacterial activity of innate immune cells, we purified $\mathrm{CD} 11 \mathrm{c}^{+} \mathrm{CD} 11 \mathrm{~b}^{+/-}$cells from the lung of $\mathrm{Ad} / \mathrm{Ad}$ animals and exposed these cells to or left them unexposed to IFN- $\beta$ before M.tb infection. After removing residual IFN- $\beta$, this cell population was infected with $M . t b$ in the presence of IFN- $\gamma$. We found that prior exposure of $\mathrm{CD} 11 \mathrm{c}^{+} \mathrm{CD} 11 \mathrm{~b}^{+/-}$cells to IFN- $\beta$ significantly hampered their ability to produce IL-12 upon $M . t b$ infection compared with their control counterparts, even in the presence of exogenous IFN- $\gamma$ (Figure 8b). As IL-12 production by innate immune cells is essential for endogenous phagocyte IFN- $\gamma$ production and subsequent release of antimycobacterial $\mathrm{NO},{ }^{33,34}$ we next measured endogenous IFN- $\gamma$ production in the above-described ex vivo model. Although M.tb infection alone was unable to induce production of IFN- $\gamma$ by this cell population, exogenous addition of IL-12 (M.tb ${ }^{+}$IL-12) significantly increased IFN- $\gamma$ production (Figure 8c). In contrast, prior exposure of this cell population to IFN- $\beta$ drastically diminished their ability to produce IFN- $\gamma$ in the presence of IL-12. Taken together, the above data suggest that the relative levels of type 1 IFN- $\beta$ in the lung induced by viral vector boost immunization regulate innate IL-12 and IFN- $\gamma$ production.

Consistent with significantly impaired IL-12 and IFN- $\gamma$ production, prior IFN $-\beta$ exposure significantly impaired the ability of $\mathrm{CD} 11 \mathrm{c}^{+} \mathrm{CD} 11 \mathrm{~b}^{+/-}$cells to produce $\mathrm{NO}$ even in the presence of both IFN- $\gamma$ and IL-12 (Figure 8d). We next examined the role of IFN- $\beta$ on the phagocytic killing ability of 

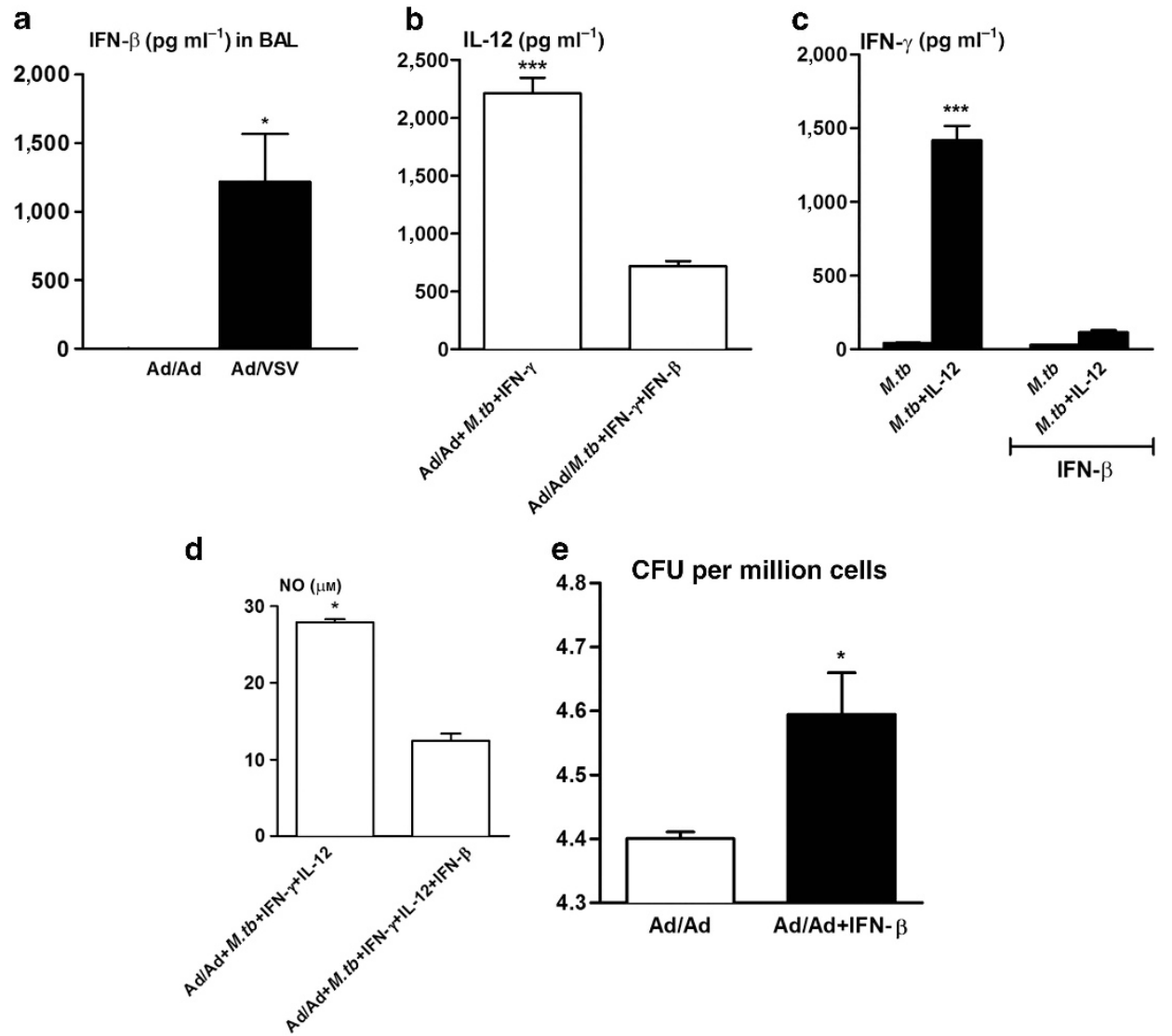

Figure 8 Type 1 interferon (IFN)- $\beta$-mediated modulation of interleukin (IL)-12 responses and innate phagocyte activation and antituberculosis (TB) activities following homologous and heterologous respiratory mucosal boost immunizations. (a) Mice were prime- and boost-immunized as depicted in Figure 1a and the levels of IFN- $\beta$ protein were determined by enzyme-linked immunosorbent assay (ELISA) in the bronchoalveolar lavage (BAL) fluids collected $24 \mathrm{~h}$ after boost immunization. Data are expressed as the mean \pm s.e.m. of IFN- $\beta$ levels from 3 mice per group. (b-d) Mice were homologous prime- and boost-immunized (adenorvirus (Ad)/Ad) as depicted in Figure 1a and lung CD11c ${ }^{+} \mathrm{CD} 11 \mathrm{~b}^{+/-}$phagocytic cell populations were purified. (b) The cells were pretreated with or without IFN- $\beta$ and then infected with Mycobacterium tuberculosis (M.tb) in the presence of IFN- $\gamma$ for $48 \mathrm{~h}$, and IL-12 protein in culture supernatants was measured by ELISA, or (c) the cells were pretreated with or without IFN- $\beta$ and then infected with M.tb in the absence or presence of IL-12 for $48 \mathrm{~h}$, and IFN- $\gamma$ protein in culture supernatants was measured by ELISA, or the cells were pretreated with or without IFN- $\beta$ and then infected with $M$.tb in the presence of both IFN- $\gamma$ and IL-12 for $48 \mathrm{~h}$, and nitric oxide (NO) in culture supernatants were measured. Results are expressed as the mean \pm s.e.m. of the levels of these molecules from triplicate samples/each, representative of two independent experiments. (e) Mice were homologous prime- and boost-immunized (Ad/Ad) as depicted in Figure 1a and lung CD11 $\mathrm{c}^{+} \mathrm{CD} 11 \mathrm{~b}^{+/-}$phagocytic cell populations were purified. The cells were pretreated with or without IFN- $\beta$ and then infected with $M$.tb for $48 \mathrm{~h}$. Cells were then lysed and intracellular mycobacterial counts were determined. Data are expressed as the mean \pm s.e.m. of colony-forming units (CFU) per $10^{6}$ cells from triplicate samples.

innate immune cells. To this end, purified $\mathrm{CD} 11 \mathrm{c}^{+} \mathrm{CD} 11 \mathrm{~b}^{+/-}$ cells from the lung of $\mathrm{Ad} / \mathrm{Ad}$ animals were exposed or left unexposed to IFN- $\beta$ before M.tb infection. After removing residual IFN- $\beta$, this cell population was then infected with $M . t b$ in vitro. The level of antimycobacterial status in these cells was determined by intracellular bacterial counts (CFU). We found that prior exposure of this population to IFN- $\beta$ made them inefficient in controlling mycobacterial infection ( $\mathrm{Ad} /$ $\mathrm{Ad}^{+}$IFN- $\beta$ ), indicated by heightened bacterial counts compared with control cell population (Ad/Ad) (Figure 8e). The above data together suggest that the relative level of type 1 IFN- $\beta$ responses to mucosal boost immunization is a critical upstream determinant of innate IL12 responses, which in turn determines the activation status of innate phagocytes and their antimycobacterial activities.

\section{DISCUSSION}

Rational design of vaccination strategies against mucosal infection rests on a good understanding of antimicrobial mucosal immunity. Viral vector-based prime-boost vaccination strategies can potently induce T-cell immunity and thus have a great potential for the fight against a number of important intracellular pathogens, including M.tb, malaria, and HIV for which effective vaccines are still lacking. ${ }^{4-8}$ In this regard, the homologous and heterologous parenteral primemucosal boost vaccination modalities are believed to be the most promising as they are able to provide both robust local mucosal and systemic protective immunity against such mucosal pathogens as M.tb and HIV. ${ }^{10-13,41}$ However, the relative potency and immune mechanisms of such homologous and heterologous mucosal boost immunizations still remain 
poorly understood. In this study, we investigated in detail the immunogenicity, protective efficacy, and immune mechanisms of homologous and heterologous virus vector-based parenteral prime-respiratory mucosal boost immunization strategies. We have found that Ad and VSV mucosal boosters are similarly potent in eliciting activated T-cell responses in the respiratory mucosa. However, they lead to drastically different immuneprotective outcomes upon mucosal M.tb challenge. The discordance of heightened T-cell responses with inferior immune protection by VSV boost immunization prompted us to unravel an innate immunity-mediated mechanism that is independent of the status of T-cell immunity in the lung. Specifically, we have identified that the relative levels of type 1 IFN responses to mucosal boost immunization dictate the level of innate IL-12 production, which in turn determines the activation and antimycobacterial activities of innate phagocytic cells, particularly $\mathrm{CD} 11 \mathrm{c}^{+}$phagocytes, in the course of pulmonary M.tb infection.

It has been well established that $\mathrm{T}$-cell immunity is critically required for natural or vaccine-activated host defense against pulmonary TB. ${ }^{2,14-16}$ One of the important mechanisms by which the $\mathrm{T}$ cell does so is to produce IFN- $\gamma$, a type 1 immune cytokine capable of robustly activating M.tb phagocytes, including macrophages and dendritic cells, and inducing NO-dependent and -independent antimycobacterial activities by these innate immune cells. ${ }^{14,15,17,42}$ Thus, the quantity and quality of Ag-specific $\mathrm{T}$ cells have conventionally been used as the sole indicator of immunogenicity and immune-protective efficacy in TB vaccine studies including clinical trials. ${ }^{18,19,43}$ However, it is increasingly realized that effective control of $M . t b$ infection involves not only $\mathrm{T}$ cells but also the responsive innate M.tb phagocytic cells. ${ }^{14,23,32}$ Indeed, it has been recently found that even in the presence of uncompromised T-cell responses, animals may still suffer increased susceptibility to primary pulmonary mycobacterial infection due to impaired macrophage/dendritic cell function. ${ }^{21,22,24,31}$ Little is known, however, whether such dichotomous innate and adaptive immune cell responses may occur to $\mathrm{TB}$ vaccination and have an impact on its immune-protective outcome. This is a particularly important issue to address in developing prime-boost vaccination strategies for mucosal infection as the large part of adaptive $\mathrm{T}$-cell activation is usually accomplished upon parenteral prime immunization and the subsequent mucosal boosting immunization would have a much greater effect on the local innate immune cells that are the integral part of host defense against microbial exposure. Thus, using models of virus-based $\mathrm{TB}$ vaccination, our study for the first time reveals that dichotomous innate and adaptive immune cell responses can also occur following respiratory mucosal boost immunization, depending on the choice of booster vaccine. Thus, in spite of similarly activated T-cell responses in the lung, differentially imprinted innate immune cells by mucosal boost immunization may still lead to different profoundly immune-protective outcomes upon mucosal M.tb challenge. Our findings together suggest that (1) the sole examination of T-cell responses, even in relevant tissue compartments (the airway lumen and lung interstitium), may not always be a reliable way to inform of the protective potential of $\mathrm{TB}$ vaccination; (2) the selection of booster vaccine vectors should be made based on their relative capability to affect both the desired innate and adaptive immune responses; and lastly, (3) the type 1 IFN-activating boost vaccine formulations may not fare well for mucosal immunization. These considerations are particularly important to developing mucosal vaccination strategies against mucosal infections by $M . t b$ and other intracellular pathogens for which host defense involves the function of macrophages and dendrite cells. ${ }^{4-8}$

By thia study, we find that Ad- and VSV-based mucosal boost immunizations lead to totally different immune-protective outcomes in the animals M.tb-challenged at two different intervals between the point of mucosal viral vector-based boosting and M.tb challenge ( 2 or 4 weeks postboosting). Future investigation is required to understand whether the VSV-imposed innate imprinting can last even longer beyond the 4-week interval. These data lend further support to the recent emerging notion that the innate imprinting by prior respiratory viral infection can be lasting and have an important impact on the subsequent immune response to a different pathogen. ${ }^{44,45}$ Furthermore, our study also provides convincing evidence to support the current conviction that the full expression of anti-TB immunity requires not only the functional $\mathrm{T}$ cells but also the APCs (M.tb-infected macrophages and DCs) that can respond to and be activatable by T cells. ${ }^{14}$ In this regard, we have previously reported that mucosal vaccine-activated $\mathrm{T}$ cells are required for much enhanced and sustained lung protection as T-cell depletion, beginning right before M.tb challenge, led to a severe loss of protection by 4 weeks post-M.tb infection. ${ }^{46}$ On the other hand, we found in this study that mucosal vaccineactivated APCs could provide a level of protection independent of $\mathrm{T}$ cells in the very early stage of M.tb infection (Supplementary Figure S1 online). The critical role of CD11c ${ }^{+}$APC activation in anti-TB immunity as shown in this study is supported further by a previous study that selective depletion of activated APCs in the lung of $M$.tb-infected mice resulted in much increased bacterial burden in the lung. ${ }^{47}$ Although our current data indicate that the impaired CD11c ${ }^{+}$ APCs resulting from VSV-mediated innate imprinting accounts for unsatisfactory immune protection, we cannot rule out a role by other innate parameters and lung microenvironment. ${ }^{44}$ For instance, it has now been shown that the innate natural killer cells are educated during development and possess Ag-specific receptors, and can undergo clonal expansion and generate long-lived memory cells during infection. ${ }^{48}$

To address whether the inferior immune-protective outcome by VSV mucosal boosting could also be due to a much lower Ag85A expression by VSV vector compared with Ad vector, we compared the relative expression of Ag85A in the lung. We found this to be unlikely as there was an even higher level of Ag85A expression in the lung of VSV animals than in Ad animals (Supplementary Figure S2 online). This finding is also in line with our previous data that the Ag85A protein 
expression in AdAg85A- and VSVAg85A-infected bronchial epithelial cells (A549 cells) was comparable even when VSV was used at a smaller dose. ${ }^{30}$ We have also performed immunohistochemistry and found that both Ad and VSV vector can transfect lung epithelial cells.

Our study reveals that compared with Ad boost immunization, the poor immune protection by mucosal VSV boost immunization was associated with heightened type 1 IFN responses. Increased IFN- $\beta$ in the lung led to markedly decreased IL-12 production by innate phagocytic cells, which in turn reduced IFN- $\gamma$ and NO production and blunted mycobactericidal activities in these innate cells. Reconstitution of IL-12 in affected cell cultures or in the lung of VSV-boosted animals restored the otherwise impaired antimycobacterial host defense. The critical role of innate IL-12 production in full activation of antimycobacterial activities in innate phagocytes is well illustrated in our ex vivo models where M.tb-infected Ad/ VSV phagocytes, even in the presence of exogenously added IFN- $\gamma$, failed to have restored $\mathrm{NO}$ production unless exogenous IL-12 was provided (Figure 7b). As activated T cells are unable to produce IL-12, these findings also explain why having only intact IFN- $\gamma$-producing $\mathrm{T}$ cells in the lung cannot overcome the defect in innate phagocyte activation imposed by type 1 IFNs. On the other hand, these findings also suggest that IL-12 acts on phagocytes via both IFN- $\gamma$-dependent and -independent mechanisms. Thus, together our data establish a mechanistic pathway that begins with mucosal boost immunization and type 1 IFN induction, and then moves down from IL-12 responses to NO production, and finally to mycobacterial control within the infected innate macrophages and dendritic cells. We further identify that among the major $\mathrm{CD} 11 \mathrm{c}^{+}$and $\mathrm{CD} 11 \mathrm{c}^{-}$phagocytic cell populations in the lung, the CD11c ${ }^{+}$ cells are most prone to the effect imposed by this IFN- $\beta-\mathrm{IL}-12$ NO-anti-TB axis. Previous studies using models of primary pulmonary M.tb infection have linked increased type 1 IFN responses to weakened host defense. ${ }^{32}$ For instance, type I IFN upregulation was associated with decreased survival of mice upon hypervirulent M.tb infection. ${ }^{49,50}$ Furthermore, induced type 1 IFN responses by poly-IC administration increased the susceptibility to primary $M$.t $b$ infection via the recruitment of a suppressive $\mathrm{CD} 11 \mathrm{~b}^{+}$myeloid population, in spite of intact Th1 immunity. ${ }^{21}$ Consistent with the evidence from the studies using other different models of intracellular infection, ${ }^{38,40}$ we found that type 1 IFNs do so by inhibiting IL-12 responses in phagocytic cells. This conclusion is supported further by a previous study that has demonstrated that certain virus infections fail to induce IL-12 and elicit high levels of type 1 IFN to negatively regulate it. ${ }^{51}$ It is also likely that type 1 IFNs may downregulate IFN- $\gamma$ receptor expression on phagocytic cells and as such blocks the activation of phagocytes by T-celland phagocyte-derived IFN- $\gamma^{21,40}$ This latter contention is supported by our observation that even exogenously introduced IFN $-\gamma$ to Ad/VSV CD11c ${ }^{+}$phagocyte cultures only partially restored their IL-12 or NO production (Figure 7a, b).

In summary, our study has revealed that differentially imprinted innate immunity by respiratory mucosal boost immunization may lead to drastically different immuneprotective outcomes, independent of T-cell immunity. The relative levels of type 1 IFNs present on the mucosal surface resulting from mucosal boost immunization have a critical role in such innate immune imprinting. Our findings hold important implications in the rational design of effective mucosal immunization strategies against mucosal intracellular pathogens.

\section{METHODS}

Mice. $\mathrm{BALB} / \mathrm{c}$ female mice (6-8 weeks old) were purchased from Harlan Laboratory (Indianapolis, IN) and housed in a specific pathogen-free, level B facility. All experiments were conducted in accordance with the guidelines of the animal research ethics board of McMaster University.

Parenteral prime and respiratory mucosal boost immunization. The development and characterization of recombinant AdAg85A and VSVAg85A vaccines has been documented previously. ${ }^{30,46}$ Mice were prime-immunized once parenteral-intramuscularly with $5 \times 10^{7}$ poreforming unit AdAg85A into the thigh quadriceps muscle as described. ${ }^{52}$ Respiratory mucosal boosting was carried out once on intramuscularly prime-immunized mice by intranasal administration of either homologous AdAg85A or heterologous VSVAg85A vaccine in $25 \mu \mathrm{l}$ of PBS 3 weeks postparenteral priming.

Total mononuclear cell isolation and purification of $\mathrm{CD}_{11 \mathrm{c}}{ }^{+}$and CD11b $^{+}$phagocytic cells. Intra-airway luminal cells were removed from lung by exhaustive BAL as described previously. ${ }^{29,46}$ After BAL, lungs were perfused through the left ventricle with Hank's buffer to remove leukocytes from the pulmonary vasculature. The lungs were then cut into small pieces and digested with collagenase type 1 (SigmaAldrich, St Louis, MO) for $1 \mathrm{~h}$ at $37^{\circ} \mathrm{C}$ before crush them through $100 \mu \mathrm{m}$ pore size filter. Splenocytes were isolated as described previously. ${ }^{29,53}$ All isolated cells were resuspended in RPMI 1640 medium supplemented with $5 \%$ fetal bovine serum and $100 \mu \mathrm{g} \mathrm{ml}^{-1}$ penicillin and streptomycin. Mononuclear cells isolated from BAL, lung, and spleen were used for intracellular cytokine staining, Ag85A tetramer staining, and cytokine production following ex vivo Ag stimulation.

The purification of $\mathrm{CD}_{11 \mathrm{c}^{+}}$and $\mathrm{CD} 11 \mathrm{~b}^{+}$phagocytic cell populations was performed as described previously. ${ }^{54}$ Briefly, total lung mononuclear cells were pooled and incubated with $\mathrm{CD} 11 \mathrm{c}$ microbeads (Miltenyi Biotec, Auburn, CA) according to the manufacturer's instructions. CD11c-labeled cells were then passed through an MS column on the OctoMACS separator (Miltenyi Biotec). Samples were run through MACS separation columns twice to achieve higher purity. The purity of $\mathrm{CD} 11 \mathrm{c}^{+} \mathrm{CD} 11 \mathrm{~b}^{+/-}$populations was consistently $>90 \%$ as determined by FACS. Following CD $11 c^{+}$cell separa tion, the negative fraction was then labeled with $\mathrm{CD} 11 \mathrm{~b}$ microbeads (Miltenyi Biotec) according to manufacturer's instruction. The purity of $\mathrm{CD}_{11 c^{-}} \mathrm{CD}_{11 \mathrm{~b}^{+}}$population was also consistently $>90 \%$.

Pulmonary M.tb challenge. M.tb H37Rv (ATCC27294) and M.tb H37Ra (ATCC25177) strains were grown in Middlebrook 7H9 broth supplemented with Middlebrook oleic acid-albumin-dextrosecatalase enrichment (Invitrogen Life Technologies, Burlington, ON, Canada), $0.002 \%$ glycerol, and $0.05 \%$ Tween- 80 for $10-15$ days, aliquoted, and stored in $-70{ }^{\circ} \mathrm{C}$ until needed. ${ }^{29,46,52}$ Before each use, $M . t b$ bacilli were washed with PBS containing $0.05 \%$ Tween- 80 twice and passed through a $27-\mathrm{G}$ needle 10 times to disperse clumps. For the challenge study with H37Ra strain, 0.5 million CFU of live bacilli were administered via the intratracheal route in $40 \mu \mathrm{l}$ of PBS. For the challenge with $\mathrm{H} 37 \mathrm{Rv}$ strain, immunized and control mice were infected intranasally with 10,000 CFU of bacilli. The level of bacterial infection was determined in the lung and spleen by plating serial dilutions of tissue homogenates in triplicates onto Middlebrook $7 \mathrm{H} 10$ 
agar plates containing oleic acid-albumin-dextrose-catalase enrichment. Plates were incubated at $37^{\circ} \mathrm{C}$ for 17 days in semisealed plastic bags. Colonies were then counted, calculated, and presented as $\log 10$ CFU per organ as described previously. ${ }^{29,46}$

Ex vivo and in vivo M.tb killing in phagocytic cells. For evaluation of in vitro antimycobacterial activity of $\mathrm{CD}_{11 \mathrm{c}^{+}} \mathrm{CD} 11 \mathrm{~b}^{+/-}$and $\mathrm{CD} 11 \mathrm{c}^{-} \mathrm{CD}_{11 \mathrm{~b}^{+}}$phagocytic cell populations, purified cells $\left(2 \times 10^{5}\right.$ cells per $2 \mathrm{ml}$ conical polypropylene tubes with O-ring screw cap (Sarstedt, Montreal, QC, Canada)) were infected with M.tb H37Ra at an multiplicity of infection of $1: 1$ in the presence of IFN- $\gamma$ $\left(0.4 \mathrm{ng} \mathrm{ml}^{-1}\right)$ and $50 \mu \mathrm{l}$ normal serum in total volume of $1 \mathrm{ml}$ cRPMI containing only penicillin. Infection was conducted at $37^{\circ} \mathrm{C}$ and $5 \%$ $\mathrm{CO}_{2}$. Extracellular bacteria were removed after $4 \mathrm{~h}$ by spinning the tubes at 1,000 r.p.m. for $8 \mathrm{~min}$. Fresh medium was added to each tube and incubated further. For determination of intracellular bacterial killing, intracellular bacterial counts were estimated at 12,24 , and $36 \mathrm{~h}$ after initial infection by plating serial dilutions. Triplicate tubes were set up for each condition and triplicate dilutions were plated. CFUs were counted after incubation of the plates at $37^{\circ} \mathrm{C}$ for 18 days. In some experiments, AG ( $2 \mathrm{~mm}$ per condition) was added to cell cultures. In other experiments, purified $\mathrm{CD} 11 \mathrm{c}^{+} \mathrm{CD} 11 \mathrm{~b}^{+/-}$cells were treated overnight with rIFN- $\beta\left(1,000 \mathrm{U} \mathrm{ml}^{-1}\right)$ before mycobacterial infection.

For evaluation of in vivo antimycobacterial activities of CD11c ${ }^{+}$ $\mathrm{CD}_{11} \mathrm{~b}^{+/-}$and CD11 $\mathrm{c}^{-} \mathrm{CD} 11 \mathrm{~b}^{+}$phagocytic cell populations in the lung, one million $\mathrm{CD} 11 \mathrm{c}^{+} \mathrm{CD} 11 \mathrm{~b}^{+/-}$and $\mathrm{CD} 11 \mathrm{c}^{-} \mathrm{CD} 11 \mathrm{~b}^{+}$cells purified from M.tb-challenged mice were lysed and intracellular bacterial counts were determined by plating serial dilution.

Cytokines measurement in BAL fluids and cell culture supernatants. For in vivo cytokine protein measurement, BAL fluids were collected and levels of IFN- $\beta$, IL-10, and IL-12p40 were measured by ELISA (R\&D Systems, Burlington, ON, Canada). Purified

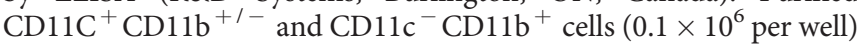
from the lung were seeded into 96 -well flat-bottomed plate and cultured with $M . t b \mathrm{H} 37 \mathrm{Ra}$ (multiplicity of infection of 1:5) at $37^{\circ} \mathrm{C}$ and $5 \% \mathrm{CO}_{2}$ in the presence or absence of recombinant IFN- $\gamma$ $\left(0.4 \mathrm{ng} \mathrm{ml}^{-1}\right)$ (R\&D Systems), or recombinant IL-12 (2 $\mathrm{ng} \mathrm{ml}^{-1}$; R\&D Systems) or both. In some instances, purified CD11C $\mathrm{CD}^{+} \mathrm{Cb}^{+1-}$ cells from the lung of homologous boost-immunized animals were cultured overnight in the presence of recombinant IFN- $\beta$ $\left(1,000 \mathrm{U} \mathrm{ml}^{-1} ; \mathrm{R} \& \mathrm{D}\right.$ Systems). Cells were then washed once and then further cultured with M.tb H37Ra in the presence or absence of rIFN- $\gamma$ or rIL-12. Cells were cultured in a total volume of $250 \mu \mathrm{l}$ of cRPMI containing only penicillin. The culture supernatants were collected at $48 \mathrm{~h}$ and stored at $-20^{\circ} \mathrm{C}$ until cytokine measurement. IFN- $\gamma$ and IL12 p40 concentrations were measured by ELISA (R\&D Systems).

Cell culture, tetramer staining, intracellular cytokine staining, immunophenotyping, and flow cytometry. Single-cell suspensions isolated from the lung and spleen were cultured in a U-bottom 96-well plate at a concentration of 20 million cells per $\mathrm{ml}$ and BAL cells were plated at a concentration of 0.5 million cells per ml. Cells were cultured and stimulated for intracellular cytokine immunostaining and FACS analysis as described previously. ${ }^{52,55}$ Briefly, cells were cultured in the presence of Golgi plug $\left(5 \mu \mathrm{g} \mathrm{ml}^{-1}\right.$ brefeldin A; BD Pharmingen, Mississauga, ON, Canada) with or without stimulation by Ag85Aspecific CD8 (MPVGGQSSF) T-cell peptides at a concentration of $1 \mu \mathrm{g}$ per well for 5-6h. Cells were then washed and blocked with CD16/ CD32 in $0.5 \%$ bovine serum albumin/PBS for $15 \mathrm{~min}$ on ice and immunostained with selected monoclonal Abs. Cells were then washed, permeabilized, and stained according to the manufacturer's instructions (BD Pharmingen). The following fluorochrome-labeled monoclonal Abs were used: CD8a-APC-Cy7, CD4-PE-Cy7, IFN- $\gamma$ $\mathrm{APC}$, and CD3-CyChrome (BD Pharmingen). For tetramer immunostaining and FACS, a tetramer for immunodominant Ag85A CD8 T-cell peptide (MPVGGQSSF) bound to the BALB/c MHC class I allele $\mathrm{H}-2 \mathrm{~L}^{\mathrm{d}}$, ordered from the MHC Tetramer Laboratory of Baylor College of Medicine (Houston, TX), was used. ${ }^{29,53}$ Cells were washed and blocked with CD16/CD32 in $0.5 \%$ bovine serum albumin/PBS for $15 \mathrm{~min}$ on ice and stained with tetramer for $1 \mathrm{~h}$ in the dark at room temperature. Cells are then washed and stained with surface Abs. Immunophenotyping of phagocytic macrophages/dendritic cells was performed as described previously. ${ }^{54}$ Briefly, cells were blocked for nonspecific binding of their Fc receptors with anti-CD16/CD32 Abs for $15 \mathrm{~min}$ and then stained for $30 \mathrm{~min}$ on ice with the appropriate combinations of fluorochrome-conjugated monoclonal Abs. Fluorochrome-conjugated monoclonal Abs to CD11c, CD11b, MHC class II, and CD3. CD3 marker was used to exclude lymphocyte population from analysis. Appropriate isotype controls were used for each Ab. For intracellular IL-10 and IL-12 production by phagocytes, lung mononuclear cells were cultured in the presence of Ag85 complex for $24 \mathrm{~h}$, in the presence of Golgi plug $\left(5 \mu \mathrm{g} \mathrm{ml}^{-1}\right.$ brefeldin A; BD Pharmingen) for the last $6 \mathrm{~h}$ of incubation. Imuunostaining was performed as described above. All of the data on immunostained cells was collected with the LSRII (BD Pharmingen) flow cytometer using FACSDiva software (BD Biosciences, San Jose, CA) and analyzed with FlowJo software (Tree Star, Ashland, OR).

NO production assay. The release of $\mathrm{NO}$ by $\mathrm{CD} 11 \mathrm{c}^{+} \mathrm{CD} 11 \mathrm{~b}^{+/-}$and $\mathrm{CD} 11 \mathrm{c}^{-} \mathrm{CD} 11 \mathrm{~b}^{+}$cells was determined by measuring the end product of NO, nitrite, as described previously. ${ }^{34}$ Briefly, diluted supernatants were added at a 1:1 ratio with Griess reagent buffer (Sigma-Aldrich). The absorbance was measured at $540 \mathrm{~nm}$ by a spectrophotometer. The final concentration of nitrite was calculated by referring to a standard curve prepared from 0 to $100 \mu \mathrm{moll}^{-1}$ of sodium nitrite concentrations.

In vivo administration of recombinant cytokines. In some experiments, recombinant IL-12 (100 ng per animal in $40 \mu \mathrm{l}$ ) was administered via the intratracheal route at different time points after mucosal boost immunization.

Ag85A mRNA expression in lung tissue by quantitative polymerase chain reaction. Mice were immunized via intranasal route either with AdAg85A or VSVAg85A. Lung lobes were harvested $36 \mathrm{~h}$ after immunization and stabilized in RNAlater (Qiagen, Valencia, CA) overnight at $4{ }^{\circ} \mathrm{C}$. Total RNA was isolated using the RNeasy kit according to the manufacturer's instructions (Qiagen). RNA (200 ng) was reversed transcribed. The reaction mixtures were incubated at $25^{\circ} \mathrm{C}$ for $5 \mathrm{~min}, 42^{\circ} \mathrm{C}$ for $30 \mathrm{~min}$, and $85^{\circ} \mathrm{C}$ for $5 \mathrm{~min}$. The expression of Ag85A was quantified by using a PerfeCTa SYBR Green FasMix, ROX kit (Quanta Bioscience, Gaithersburg, MD) on an ABI 7900HT sequence detection system (Applied Biosystems, Foster City, CA). Expression levels of Ag85A were normalized to $\beta$-actin within the sample and expressed as fold change over the Ad vector. Primer sequences were designed using NCBI primer-BLAST (NCBI, Bethesda, MD). The specificity of the primer probe sets was determined by analyzing the melt curve of the amplified product using ABI 7900HT sequence detection system (Applied Biosystems). The sequences of PCR sense and antisense primers for $\mathrm{Ag} 85 \mathrm{~A}$ gene were $5^{\prime}$ CAACCTGCCGGCCAAGTTCCT- $3^{\prime}$ and $5^{\prime}$-GGCACGGCGTTGG GCGT-3', respectively. The sequences of PCR sense and antisense primers for $\beta$-actin were $5^{\prime}$-TCTGGCACCACACCTTCTA- $3^{\prime}$ and 5'-AGGCATACAGGGACAGCAC-3', respectively.

Data analysis. Asterisk mark $\left({ }^{*},{ }^{*}\right.$, and $\left.{ }^{* * *}\right)$ in the figures indicate the differences deemed statistically significant $(P<0.05, P<0.01$, and $P<0.001$, respectively). A two-tailed Student's $t$-test was performed for pairwise comparisons. One-way analysis of variance and the subsequent Tukey's post hoc test were carried out for the comparison of multiple groups. All statistical analyses were performed by using GraphPad Prism software (GraphPad Software, La Jolla, CA).

SUPPLEMENTARY MATERIAL is linked to the online version of the paper at http://www.nature.com/mi 


\section{ACKNOWLEDGEMENTS}

We thank the BEI Resources for providing us with M.tb Ags, and we also thank Xueya Feng and Natasha Kazhdan for providing technical assistance. This work was supported by funds from the Canadian Institutes for Health Research.

\section{DISCLOSURE}

The authors declared no conflict of interest.

c) 2013 Society for Mucosal Immunology

\section{REFERENCES}

1. McShane, H. Prime-boost immunization strategies for infectious diseases. Curr. Opin. Mol. Ther. 4, 23-27 (2002).

2. Nolz, J.C. \& Harty, J.T. Strategies and implications for prime-boost vaccination to generate memory CD8 T cells. Adv. Exp. Med. Biol. 780, 69-83 (2011).

3. Woodland, D.L. Jump-starting the immune system: prime-boosting comes of age. Trends Immunol. 25, 98-104 (2004).

4. Draper, S.J. \& Heeney, J.L. Viruses as vaccine vectors for infectious diseases and cancer. Nat. Rev. Microbiol. 8, 62-73 (2010).

5. Rollier, C.S., Reyes-Sandoval, A., Cottingham, M.G., Ewer, K. \& Hill, A.V. Viral vectors as vaccine platforms: deployment in sight. Curr. Opin. Immunol. 23, 377-382 (2011).

6. Xing, Z. et al. Recent advances in the development of adenovirus- and poxvirus-vectored tuberculosis vaccines. Curr. Gene Ther. 5, 485-492 (2005).

7. Radosevic, K., Rodriguez, A., Lemckert, A. \& Goudsmit, J. Heterologous prime-boost vaccinations for poverty-related diseases: advantages and future prospects. Expert Rev. Vaccines 8, 577-592 (2009).

8. Paris, R.M., Kim, J.H., Robb, M.L. \& Michael, N.L. Prime-boost immunization with poxvirus or adenovirus vectors as a strategy to develop a protective vaccine for HIV-1. Expert Rev. Vaccines 9, 1055-1069 (2010).

9. Holmgren, J. \& Czerkinsky, C. Mucosal immunity and vaccines. Nat. Med. 11 (Suppl), S45-S53 (2005).

10. Ranasinghe, C. \& Ramshaw, I.A. Genetic heterologous prime-boost vaccination strategies for improved systemic and mucosal immunity. Expert Rev. Vaccines 8, 1171-1181 (2009).

11. Belyakov, I.M. \& Ahlers, J.D. What role does the route of immunization play in the generation of protective immunity against mucosal pathogens? J. Immunol. 183, 6883-6892 (2009).

12. Belyakov, I.M., Moss, B., Strober, W. \& Berzofsky, J.A. Mucosal vaccination overcomes the barrier to recombinant vaccinia immunization caused by preexisting poxvirus immunity. Proc. Natl. Acad. Sci. USA 96, 4512-4517 (1999).

13. Croyle, M.A. et al. Nasal delivery of an adenovirus-based vaccine bypasses pre-existing immunity to the vaccine carrier and improves the immune response in mice. PLoS One 3, e35482008.

14. Cooper, A.M. T cells in mycobacterial infection and disease. Curr. Opin. Immunol. 21, 378-384 (2009).

15. Jeyanathan, M., Heriazon, A. \& Xing, Z. Airway luminal T cells: a newcomer on the stage of TB vaccination strategies. Trends Immunol. 31, 247-252 (2010).

16. Seder, R.A., Darrah, P.A. \& Roederer, M. T-cell quality in memory and protection: implications for vaccine design. Nat. Rev. Immunol. 8, 247-258 (2008).

17. Urdahl, K.B., Shafiani, S. \& Ernst, J.D. Initiation and regulation of T-cell responses in tuberculosis. Mucosal Immunol. 4, 288-293 (2011).

18. Barker, L.F., Brennan, M.J., Rosenstein, P.K. \& Sadoff, J.C. Tuberculosis vaccine research: the impact of immunology. Curr. Opin. Immunol. 21 331-338 (2009).

19. Hanekom, W.A. et al. Immunological outcomes of new tuberculosis vaccine trials: WHO panel recommendations. PLoS Med. 5, e1452008).

20. Ottenhoff, T.H. et al. First in humans: a new molecularly defined vaccine shows excellent safety and strong induction of long-lived Mycobacterium tuberculosis-specific Th1-cell like responses. Hum. Vaccine 6, 1007-1015 (2010).
21. Antonelli, L.R. et al. Intranasal poly-IC treatment exacerbates tuberculosis in mice through the pulmonary recruitment of a pathogen-permissive monocyte/macrophage population. J. Clin. Invest. 120, 1674-1682 (2010).

22. Potian, J.A., Rafi, W., Bhatt, K., McBride, A., Gause, W.C. \& Salgame, P. Preexisting helminth infection induces inhibition of innate pulmonary antituberculosis defense by engaging the IL-4 receptor pathway. J. Exp. Med. 208, 1863-1874 (2011).

23. Shaler, C.R., Horvath, C., Lai, R. \& Xing, Z. Understanding delayed T-cell priming, lung recruitment, and airway luminal T-cell responses in host defense against pulmonary tuberculosis. Clin. Dev. Immunol. 2012, 628293 (2012)

24. Zganiacz, A. et al. TNF-alpha is a critical negative regulator of type 1 immune activation during intracellular bacterial infection. J. Clin. Invest. 113, 401-413 (2004).

25. Neutra, M.R. \& Kozlowski, P.A. Mucosal vaccines: the promise and the challenge. Nat. Rev. Immunol. 6, 148-158 (2006).

26. Barouch, D.H. et al. Immunogenicity of recombinant adenovirus serotype 35 vaccine in the presence of pre-existing anti-Ad5 immunity. J. Immunol. 172, 6290-6297 (2004).

27. Casimiro, D.R. et al. Comparative immunogenicity in rhesus monkeys of DNA plasmid, recombinant vaccinia virus, and replication-defective adenovirus vectors expressing a human immunodeficiency virus type 1 gag gene. J. Virol. 77, 6305-6313 (2003).

28. Shiver, J.W. et al. Replication-incompetent adenoviral vaccine vector elicits effective anti-immunodeficiency-virus immunity. Nature 415, 331-335 (2002).

29. Santosuosso, M., Zhang, X., McCormick, S., Wang, J., Hitt, M. \& Xing, Z. Mechanisms of mucosal and parenteral tuberculosis vaccinations: adenoviral-based mucosal immunization preferentially elicits sustained accumulation of immune protective CD4 and CD8 Tcells within the airway lumen. J. Immunol. 174, 7986-7994 (2005).

30. Roediger, E.K., Kugathasan, K., Zhang, X., Lichty, B.D. \& Xing, Z. Heterologous boosting of recombinant adenoviral prime immunization with a novel vesicular stomatitis virus-vectored tuberculosis vaccine. Mol. Ther. 16, 1161-1169 (2008)

31. Fremond, C.M., Yeremeev, V., Nicolle, D.M., Jacobs, M., Quesniaux, V.F. \& Ryffel, B. Fatal Mycobacterium tuberculosis infection despite adaptive immune response in the absence of MyD88. J. Clin. Invest. 114, 1790-1799 (2004).

32. Cooper, A.M., Mayer-Barber, K.D. \& Sher, A. Role of innate cytokines in mycobacterial infection. Mucosal Immunol. 4, 252-260 (2011).

33. Wang, J., Wakeham, J., Harkness, R. \& Xing, Z. Macrophages are a significant source of type 1 cytokines during mycobacterial infection. J. Clin. Invest. 103, 1023-1029 (1999).

34. Xing, Z., Zganiacz, A. \& Santosuosso, M. Role of IL-12 in macrophage activation during intracellular infection: IL-12 and mycobacteria synergistically release TNF-alpha and nitric oxide from macrophages via IFNgamma induction. J. Leukoc. Biol. 68, 897-902 (2000).

35. Redford, P.S., Murray, P.J. \& O'Garra, A. The role of IL-10 in immune regulation during M. tuberculosis infection. Mucosal Immunol. 4, 261-270 (2011).

36. McCormick, S., Shaler, C.R. \& Xing, Z. Pulmonary mucosal dendritic cells in T-cell activation: implications for TB therapy. Expert Rev. Respir. Med. 5, 75-85 (2011).

37. Cooper, A.M., Roberts, A.D., Rhoades, E.R., Callahan, J.E., Getzy, D.M. \& Orme, I.M. The role of interleukin-12 in acquired immunity to Mycobacterium tuberculosis infection. Immunology 84, 423-432 (1995).

38. Byrnes, A.A. et al. Type I interferons and IL-12: convergence and crossregulation among mediators of cellular immunity. Eur. J. Immunol. 31, 2026-2034 (2001)

39. Cousens, L.P., Orange, J.S., Su, H.C. \& Biron, C.A. Interferon-alpha/beta inhibition of interleukin 12 and interferon-gamma production in vitro and endogenously during viral infection. Proc. Natl. Acad. Sci. USA 94, 634-639 (1997).

40. Rayamajhi, M., Humann, J., Penheiter, K., Andreasen, K. \& Lenz, L.L. Induction of IFN-alphabeta enables Listeria monocytogenes to suppress macrophage activation by IFN-gamma. J. Exp. Med. 207, 327-337 (2010).

41. Xing, Z. \& Lichty, B.D. Use of recombinant virus-vectored tuberculosis vaccines for respiratory mucosal immunization. Tuberculosis (Edinb) 86, 211-217 (2006). 
42. Yan, B.S. et al. Progression of pulmonary tuberculosis and efficiency of bacillus Calmette-Guerin vaccination are genetically controlled via a common sst1-mediated mechanism of innate immunity. J. Immunol. 179, 6919-6932 (2007).

43. Beveridge, N.E. et al. A comparison of IFNgamma detection methods used in tuberculosis vaccine trials. Tuberculosis (Edinb) 88, 631-640 (2008).

44. Goulding, J. et al. Respiratory infections: do we ever recover?. Proc. Am. Thorac. Soc. 4, 618-625 (2007).

45. Sui, Y. et al. Innate and adaptive immune correlates of vaccine and adjuvant-induced control of mucosal transmission of SIV in macaques. Proc. Natl. Acad. Sci. USA 107, 9843-9848 (2010).

46. Wang, J. et al. Single mucosal, but not parenteral, immunization with recombinant adenoviral-based vaccine provides potent protection from pulmonary tuberculosis. J. Immunol. 173, 6357-6365 (2004).

47. Leemans, J.C. et al. Macrophages play a dual role during pulmonary tuberculosis in mice. J. Infect. Dis. 191, 65-74 (2005).

48. Sun, J.C. \& Lanier, L.L. Versatility in NK cell memory. Immunol. Cell. Biol. 89, 327-329 (2011).

49. Manca, C. et al. Virulence of a Mycobacterium tuberculosis clinical isolate in mice is determined by failure to induce Th1 type immunity and is associated with induction of IFN-alpha/beta. Proc. Natl. Acad. Sci. USA 98, 5752-5757 (2001).
50. Manca, C. et al. Hypervirulent M. tuberculosis W/Beijing strains upregulate type I IFNs and increase expression of negative regulators of the Jak-Stat pathway. J Interferon Cytokine Res. 25, 694-701 (2005).

51. Cousens, L.P. et al. Two roads diverged: interferon alpha/beta- and interleukin 12-mediated pathways in promoting $T$ cell interferon gamma responses during viral infection. J. Exp. Med. 189, 1315-1328 (1999).

52. Santosuosso, M. et al. Mucosal luminal manipulation of T cell geography switches on protective efficacy by otherwise ineffective parenteral genetic immunization. J. Immunol. 178, 2387-2395 (2007).

53. Santosuosso, M., McCormick, S., Zhang, X., Zganiacz, A. \& Xing, Z. Intranasal boosting with an adenovirus-vectored vaccine markedly enhances protection by parenteral Mycobacterium bovis BCG immunization against pulmonary tuberculosis. Infect. Immun. 74, 4634-4643 (2006).

54. Kugathasan, K., Roediger, E.K., Small, C.L., McCormick, S., Yang, P. \& Xing, Z. $\mathrm{CD}_{11 \mathrm{C}^{+}}$antigen presenting cells from the alveolar space, lung parenchyma and spleen differ in their phenotype and capabilities to activate naive and antigen-primed T cells. BMC Immunol. 9, 48 (2008).

55. Santosuosso, M., McCormick, S. \& Xing, Z. Adenoviral vectors for mucosal vaccination against infectious diseases. Viral Immunol. 18, 283-291 (2005). 